\title{
Seismic Noise Parameters as Indicators of Reversible Modifications in Slope Stability: A Review
}

\author{
C. Colombero ${ }^{1}$ (D) - D. Jongmans ${ }^{2} \cdot$ S. Fiolleau ${ }^{2} \cdot$ J. Valentin $^{2} \cdot$ L. Baillet $^{2} \cdot$ G. Bièvre $^{2}$
}

Received: 11 May 2020 / Accepted: 20 January 2021 / Published online: 9 February 2021

(c) The Author(s) 2021

\begin{abstract}
Continuous ambient seismic monitoring of potentially unstable sites is increasingly attracting the attention of researchers for precursor recognition and early warning purposes. Twelve cases of long-term continuous noise monitoring have been reported in the literature between 2012 and 2020. Only in a few cases rupture was achieved and irreversible drops in resonance frequency values or shear wave velocity extracted from noise recordings were documented. On the other hand, all monitored sites showed clear reversible fluctuations of the seismic parameters on a daily and seasonal scale due to changes in external weather conditions (air temperature and precipitation). A quantitative comparison of these reversible modifications is used to gain insight into the mechanisms driving the site seismic response. Six possible mechanisms were identified, including three temperature-driven mechanisms (temperature control on fracture opening/closing, superficial stress conditions and bulk rigidity), one precipitation-driven mechanism (water infiltration effect) and two mechanisms sensitive to both temperature and precipitation (ice formation and clay behavior). The reversible variations in seismic parameters under the meteorological constraints are synthesized and compared to the irreversible changes observed prior to failure in different geological conditions.
\end{abstract}

Keywords Seismic noise $\cdot$ Slope stability $\cdot$ Resonance frequency $\cdot$ Seismic interferometry Reversible modifications · Meteorological factors

\section{Article Highlights}

- Ambient seismic noise monitoring can reveal reversible and irreversible changes within potentially unstable volumes.

- Reversible modifications in resonance frequency and shear wave velocity are driven by air temperature and/or precipitation.

- A quantitative evaluation of the reversible modifications is needed for correctly identifying failure precursors.

C. Colombero

chiara.colombero@polito.it

Extended author information available on the last page of the article 


\section{Introduction}

In the last decade, there have been growing applications of long-term continuous ambient seismic noise systems to monitor landslides and potentially unstable rock sites. Two main monitoring parameters can be alternatively or concurrently extracted from noise recording at potentially unstable sites: The fundamental resonance frequency $(f l)$ of the unstable compartments can be derived from noise spectral analysis (e.g., Bottelin et al. 2013a; Starr et al. 2015; Colombero et al. 2017; Burjánek et al. 2018; Iannucci et al. 2020), while internal shear wave velocity changes $(\mathrm{d} V / V)$ can be detected from noise cross-correlation (e.g., Mainsant et al. 2012; Larose et al. 2015; Colombero et al. 2018; Fiolleau et al. 2020).

The detection of irreversible drops in resonance frequency values and/or of negative velocity changes uncorrelated with external meteorological factors is of primary interest. Both $f 1$ and $\mathrm{d} V / V$ are indeed easy-to-monitor seismic parameters, whose irreversible modifications may be read as precursors to failure and therefore used for monitoring and early warning purposes. In particular, since $f l$ value is directly related to the mechanical properties of the unstable compartment, the degradation of mechanical properties leading to failure can be tracked by a progressive drop in $f l$. At the same time, the seismic velocity is expected to decrease for the same reasons (negative $\mathrm{d} V / V$ ).

However, despite the increasing number of studies, only in a few monitored cases slope failure was approached (Lévy et al. 2010; Mainsant et al. 2012; Bertello et al. 2018; Fiolleau et al. 2020) and irreversible modifications in $f 1$ and $\mathrm{d} V / V$ were recorded. Lévy et al. (2010) detected a significant decrease (-30\%) in $f 1$ two weeks before the collapse of a $21,000-\mathrm{m}^{3}$ limestone column. This drop was interpreted as the consequence of stiffness loss due to the breakage of the rock bridges connecting the column to the stable cliff. Mainsant el al. (2012) showed that the seismic velocity of an earthflow (i.e., Pont Bourquin landslide, reviewed in the following) continuously and rapidly decreased $(-7 \%)$ for several days prior to an earthslide event of few thousand cubic meters. This negative $\mathrm{d} V / V$ was interpreted as resulting from the decay in the landslide material rigidity. Bertello et al. (2018) carried out periodic and continuous measurements of Rayleigh wave velocity in an active earthflow located in the northern Apennines (Italy). The landslide material exhibited substantial drops in velocity as the earthflow accelerated ( $\mathrm{d} V / V$ up to $-50 \%$ ), linked to significant changes in shear stiffness and undrained strength during rapid movements. Recently, Fiolleau et al. (2020) analyzed the four-month ambient seismic noise data recorded before a clay block collapse in Harmalière landslide (reviewed in the following). Two seismic stations were installed on either side of a developing rear fracture progressively isolating the unstable block volume. In the hours preceding failure, a drop in $f 1$ value (approximately $-25 \%$ ) uncorrelated with external meteorological conditions was recorded at the top of the block, while $\mathrm{d} V / V$ trend became unclear probably due to the loss of correlation between the recordings of the two stations, marked by a decrease in the correlation coefficient values. Both $f 1$ and correlation drops were interpreted as the consequence of progressive fracture opening and stiffness loss leading to the block collapse.

Although the failure stage was monitored only in these four studies, all the continuously monitored sites showed reversible fluctuations in the seismic parameters over time, interpreted as driven by modifications in external meteorological conditions. The objective of this work is to review and interpret all the existing case histories reporting $f 1$ and $\mathrm{d} V / V$ reversible modifications, in order to identify, understand and classify the related driving mechanisms. The review is consequently limited to case studies in which ambient seismic noise was continuously recorded, for a time period ranging from few days to several 
years. Based on these criteria, twelve applications are found in the literature for the period between 2012 and 2020, including eight rock sites and four landslides in destructured or loose materials (references in Table 1). The majority of these sites are potentially unstable rock masses located in the Alpine context (France, Switzerland and Italy). Daily and seasonal $f 1$ and $\mathrm{d} V / V$ fluctuations recorded in the different studies are here collected, quantified and compared with temperature and rainfall trends at each site.

Both positive and negative correlations between seismic parameters and meteorological factors are highlighted, with different time of response (delay) of $f l$ and $\mathrm{d} V / V$ to the meteorological changes. We have critically analyzed the physical phenomena introduced to explain these reversible variations and proposed a classification into six driving mechanisms. Understanding the causes of these reversible variations offers valuable information on site stability and is a fundamental prerequisite for the correct identification of irreversible drops in the seismic parameters which can be read as possible precursors to rupture.

\section{Methods}

\subsection{Noise Spectral Analysis}

The concept of resonance frequency applied to gravitational instabilities develops from the analogy between unstable sites and a simple oscillator, which is characterized by a

Table 1 Case studies of long-term continuous ambient seismic noise monitoring reported in the literature for the period between 2012 and 2020

\begin{tabular}{|c|c|c|c|}
\hline Site & Location & Acronym & References \\
\hline Les Arches & Vercors Massif, France & LA & $\begin{array}{l}\text { Bottelin et al. (2013a) } \\
\text { Bottelin et al. (2013b) } \\
\text { Bottelin (2014) }\end{array}$ \\
\hline La Bourne & Vercors Massif, France & LB & Bottelin et al. (2017) \\
\hline Bory Crater & Piton de la Fournaise, Reunion & $\mathrm{BC}$ & $\begin{array}{l}\text { Bottelin (2014) } \\
\text { Valentin et al. (2017) }\end{array}$ \\
\hline Alpe di Roscioro & Alps, Switzerland & AR & Burjánek et al. (2018) \\
\hline Matterhorn Hörnligrat & Alps, Switzerland & $\mathrm{MH}$ & Weber et al. (2018) \\
\hline Madonna del Sasso & Alps, Italy & MS & $\begin{array}{l}\text { Colombero et al. (2017) } \\
\text { Colombero et al. (2018) }\end{array}$ \\
\hline Mesa Arch & Utah, USA & MA & Starr et al. (2015) \\
\hline Char d'Osset & Alps, France & $\begin{array}{l}\text { COt (top sector) } \\
\text { COb (bottom sector) }\end{array}$ & Valentin (2018) \\
\hline Pont Bourquin & Alps, Switzerland & PB & $\begin{array}{l}\text { Mainsant et al. (2012) } \\
\text { Larose et al. (2015) } \\
\text { Carrière (2016) } \\
\text { Bièvre et al. (2018) }\end{array}$ \\
\hline Harmalière & Alps, France & HA & Fiolleau et al. (2020) \\
\hline La Praz & Alps, France & LP & $\begin{array}{l}\text { Bottelin et al. (2013a) } \\
\text { Bottelin (2014) }\end{array}$ \\
\hline
\end{tabular}


resonance frequency $f l$, increasing with the stiffness $K$ and decreasing with the mass $M$ of the system, following:

$$
f 1=\frac{1}{2 \pi} \sqrt{\frac{K}{M}} .
$$

For a slender beam of square section in flexural vibration, Chen and Lui (1997) introduced the relation:

$$
f i=\frac{k_{i}}{2 \pi} \frac{L}{z^{2}} \sqrt{\frac{E}{12 \rho}}(i=1,2, \ldots)
$$

where $k_{i}$ is a numeric coefficient depending on the resonant mode $i\left(k_{l}=1.875\right.$ for the first vibration mode), $L$ and $z$ describe the geometry of the beam, being the length of the square side and free height, respectively, $E$ and $\rho$ are the Young's modulus and density of the beam material, respectively.

Similar to Eqs. 1 and 2, a prone-to-fall compartment, with width $L$ and rear fracture depth $z$ (Fig. 1), has resonance frequencies, whose values are controlled by its mass $M$ (i.e., volume and density) and mechanical properties. The latter include the internal stiffness $\left(K_{b}\right)$ of the unstable compartment, which can be described with Young's modulus of the bulk material $\left(E_{b}\right)$, and the stiffness at the contact between the stable rock mass and the unstable compartment $\left(K_{c}\right) . K_{c}$ is a function of the fracture properties (e.g., depth, width, roughness, filling material, presence of intact rock bridges) and thus usually difficult to describe and quantify.

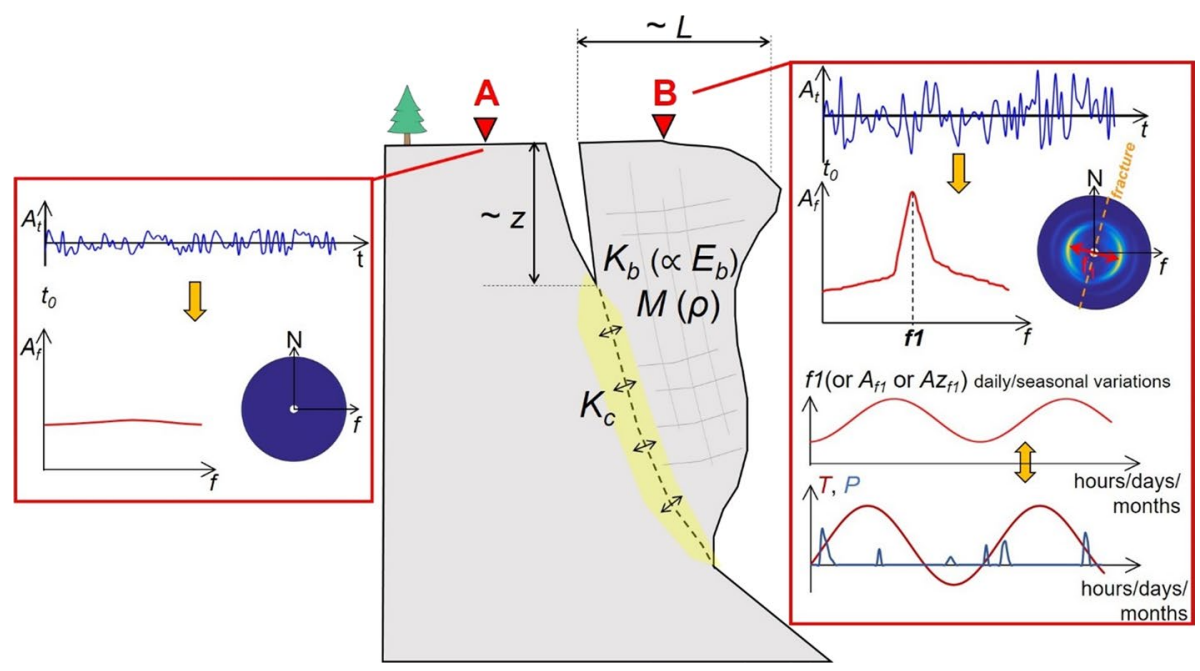

Fig. 1 Spectral analysis of ambient seismic noise recorded on an unstable site (A: stable reference station, B: station on unstable column). Station A does not highlight spectral amplifications and directivities in the considered frequency band. The resonance frequency $(f 1)$ of the unstable compartment is conversely extracted from the power spectral density (PSD) of the noise recorded at station B, and the directivity of the frequency peak can be analyzed as a function of fracture orientation. The resonance frequency $f 1$ (as well as the peak amplitude $A_{f l}$ and azimuthal direction $A z_{f l}$ ) can be monitored over time and compared with meteorological factors ( $T$ : air temperature, $P$ : precipitation). Geometric and mechanical parameters are defined in the text 
Valentin et al. (2017) performed 2-D numerical modeling of a rock column isolated by a single vertical rear fracture to assess the pertinent and applicable parameters that could be extracted from ambient vibrations and used to gain information on a prone-to-fall column in stiff rock conditions. In analogy with Eq. 2, it was found that $f l$ value (first bending resonance frequency) depends on both the column geometry (thickness $\mathrm{L}$ and depth $\mathrm{z}$, in $m$ ) and the rock Young's modulus $E_{b}$ (in GPa), following:

$$
f 1=44.696 L^{0.486} z^{-1.507} E_{b}^{0.49} .
$$

Resonance frequency values can be derived from the peaks in the power spectral density (PSD) of continuous noise recordings (following Bendat and Piersol 1971; McNamara and Buland, 2004). Single-station (e.g., H/V method) or site-reference (i.e., between the same component of two different stations, e.g., V/V, E/E, N/N or H/H) spectral ratios may be complementarily used to enhance the spectral peaks characterizing the site, following Burjánek et al. $(2010,2012)$. The 3-D spatial directivity of these spectral peaks can provide additional information on the structural constraints of the potentially unstable volumes. In particular, the wave polarization in the horizontal plane was shown to be controlled by the vertical fracture pattern at several sites (e.g., Bottelin et al. 2013a; Colombero et al. 2017; Burjánek et al. 2018).

Following Eqs. 1, 2 and 3, irreversible drops in $f 1$ values over the monitored period can be interpreted as a loss in internal or contact stiffness and therefore be read as potential precursors to failure (Lévy et al. 2010). However, even if failure does not occur, minor reversible fluctuations in resonance frequency are systematically reported in the literature (detailed references in Table 1). These fluctuations are interpreted as a consequence of changes in meteorological parameters (mainly air temperature $T$ and precipitation $P$ ), which may modify the internal properties of the unstable compartments over different timescales. It should be noted that not only resonance frequency values, but also the amplitude of the spectral peaks (both in PSDs and in spectral ratios) and the azimuth of vibration can vary over time depending on weather conditions (e.g., Valentin et al. 2017; Colombero et al. 2018). However, since the available literature is based primarily on fluctuations in resonance frequency values, thermal and hydrological controls on spectral amplitudes and directivities will not be examined in the following. Higher modes $(f 2, f 3, \ldots)$ are excluded from the discussion as well, since their number, values and vibration properties are strictly site-dependent and the related fluctuations as a function of meteorological factors are not ubiquitously analyzed in the reference case studies.

\subsection{Noise Cross-Correlation}

Reversible and irreversible modifications (i.e., seismic velocity changes) within the unstable bodies can be alternatively or complementarily extracted from cross-correlation of ambient seismic noise (Larose et al. 2005). Theoretical and experimental studies have shown that for a pair of stations (e.g., site-reference configuration, Fig. 2) simultaneously recording diffuse wavefields (e.g., ambient noise or scattered coda waves), cross-correlation of the recordings provides an estimate of the Green's function between the two locations, as if an active source and a receiver were placed at the two sensor locations, respectively (Derode et al. 2003; Weaver and Lobkis 2001; Snieder 2004; Wapenaar 2004; Shapiro and Campillo 2004; Paul et al. 2005; Sabra et al. 2005). The requirements to converge to the Green's function from noise cross-correlation are highlighted in several studies (Curtis et al. 2006; Sato 2009; Larose et al. 2015). For the reconstruction of surface waves, 


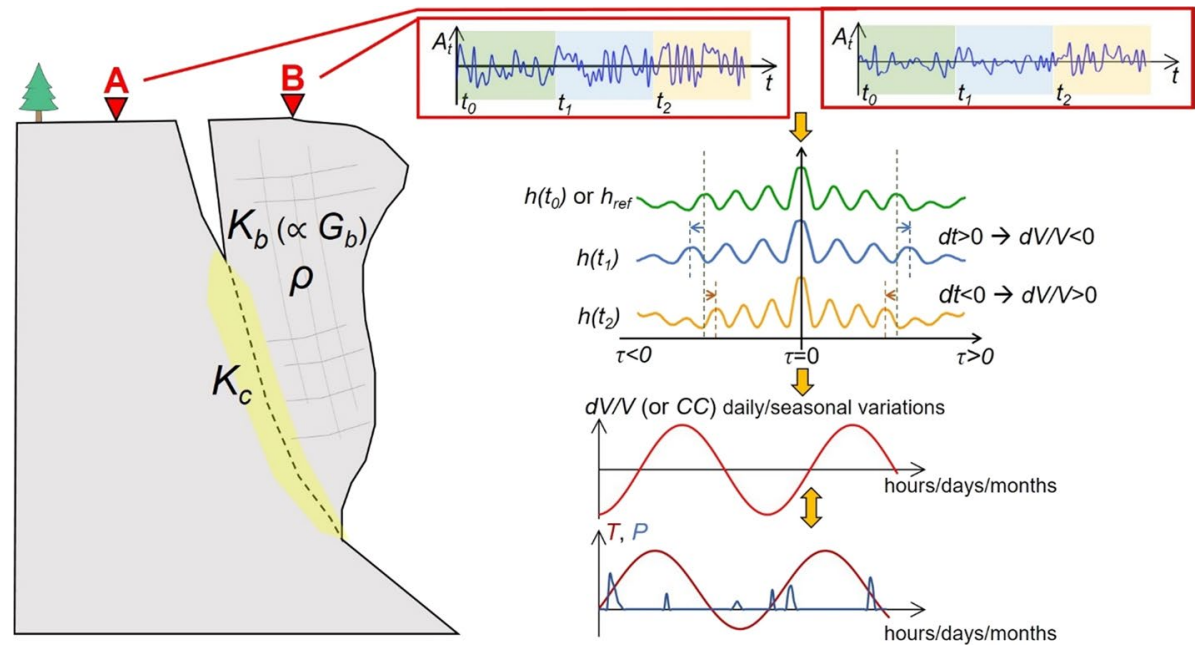

Fig. 2 Cross-correlation of ambient seismic noise between a couple of sensors (A: stable reference station, B: station on unstable column). The green, blue and yellow backgrounds highlight different time windows (e.g., hours or days) in the continuous recordings. The hourly or daily cross-correlograms (colored curves) obtained between noise recorded at $\mathrm{A}$ and $\mathrm{B}$ on these windows are stretched along the time axis to maximize the correlation coefficient $(C C)$ with respect to a reference correlogram $\left(\mathbf{h}_{\text {ref }}\right.$, first time window or average over the whole or a part of the monitored period) and retrieve the shear wave velocity change $\mathrm{d} V / V$ (e.g., $\mathbf{h}\left(\mathbf{t}_{1}\right)$ and $\mathbf{h}\left(\mathbf{t}_{2}\right)$ are correlograms after a negative and positive velocity change, respectively). Both $\mathrm{d} V / V$ and $C C$ can be monitored over time and compared with meteorological factors $(T$ : air temperature, $P$ : precipitation)

noise sources must be uncorrelated in time and located all around the receivers (without preferential directions) and the wavefield must be equipartitioned in a proper ratio of compressional and shear waves. Nevertheless, scattering and mode conversion at the subsurface interfaces and discontinuities profitably compensate for the above conditions (Weaver and Lobkis 2001; Paul et al. 2005). In addition, laboratory experiments (Hadziioannou et al. 2009) demonstrated that even if a portion of the noise sources differ over time and thus the reconstruction of the Green's function is imperfect, cross-correlation monitoring still succeeds in detecting mechanical changes within the investigated medium.

The theoretical assumption under the cross-correlation method is that, in the case of a homogeneous velocity change within the investigated medium between stations A and B (Fig. 2), the cross-correlograms (h) computed after this perturbation are shifted in time $(t)$ by a factor $\mathrm{d} V / V$, following (Larose et al. 2015):

$$
\frac{\mathrm{d} V}{V}=\frac{-\mathrm{d} t}{t}
$$

The stretching technique (Sens-Schönfelder and Wegler 2006; Hadziioannou et al. 2009) can be applied to measure this relative velocity change. This method consists in testing several possible $\mathrm{d} V / V$ values, by filtering the correlograms in narrow frequency bands, with central frequency $f_{c}$, and resampling them in time (stretching of the time axis), following Poupinet et al. (1984): 


$$
h_{f_{c}} \rightarrow h_{f_{c}}\left(t\left(1-\frac{\mathrm{d} V}{V}\right)\right)
$$

with respect to a reference correlogram $\mathbf{h}_{\text {ref }}$ which can be the first, a specific part (i.e., a stable period) or the average correlogram over the recorded time period. The optimal relative velocity change $\mathrm{d} V / V$ is the one that maximizes the correlation coefficient CC:

$$
\operatorname{CC}\left(\frac{\mathrm{d} V}{V}\right)=\frac{\int h_{\mathrm{fc}}\left(t\left(1-\frac{\mathrm{d} V}{V}\right)\right) h_{\mathrm{ref}}(t) \mathrm{d} t}{\sqrt{\int h_{\mathrm{fc}}^{2}\left(t\left(1-\frac{\mathrm{d} V}{V}\right)\right) \mathrm{d} t \int h_{\mathrm{ref}}^{2}(t) \mathrm{d} t}} .
$$

As a consequence, noise cross-correlation gives direct access to the relative velocity change within the medium. The stretching computation is performed in the late part of the correlograms to avoid body wave paths between the two receivers and benefit from later surface wave arrivals in the coda (Mainsant et al. 2012). The latter have sampled the medium more densely with longer scattered paths and are therefore more sensitive to subtle velocity variations within the unstable compartments. The detected change in surface wave velocity $(\mathrm{d} V / V)$ at a given frequency is mainly related to a variation in shear wave velocity at a depth depending on this frequency (Mainsant et al. 2012). $V_{s}$ is given by:

$$
V_{s}=\sqrt{\frac{G}{\rho}},
$$

where $G$ is the shear modulus (modulus of rigidity) and $\rho$ is the density of the medium. The depth of investigation is inversely related to the considered frequency band (centered on $f_{c}$ ) on which $\mathrm{d} V / V$ is computed by the stretching technique.

Since a decrease in rigidity causing slope failure induces an irreversible negative velocity variation, seismic noise cross-correlation can be potentially used for early warning monitoring purposes. This drop in $\mathrm{d} V / V$ is usually combined with a simultaneous drop in the $\mathrm{CC}$ values (Mainsant et al. 2012). However, meteorological variations can also induce reversible $\mathrm{d} V / V$ and $\mathrm{CC}$ fluctuations due to temporary thermal and hydrological modifications within the unstable compartments affecting rigidity and/or density (Bièvre et al. 2018).

\section{Characteristics of the Study Sites}

We found twelve case studies of long-term seismic noise monitoring (applying spectral analysis and/or cross-correlation) at potentially unstable sites in the literature between 2012 and 2020.

Their geographical location is shown in Fig. 3. Detailed site descriptions, images and maps can be found in the reference studies listed in Table 1; the main geological and geometrical features are, however, summarized in Table 2, while seismic instrumentations and monitored times are detailed in Table 3.

Ten sites are located in the Alps, between France, Switzerland and Italy (Fig. 3b). One location (Char d'Osset) includes two separated subsites: the hill top (COt) and a gully $(\mathrm{COb})$ where rock falls and debris flows are generated. The remaining case histories include a natural arch from the Canyonlands National Park (Mesa Arch, Utah, USA, 

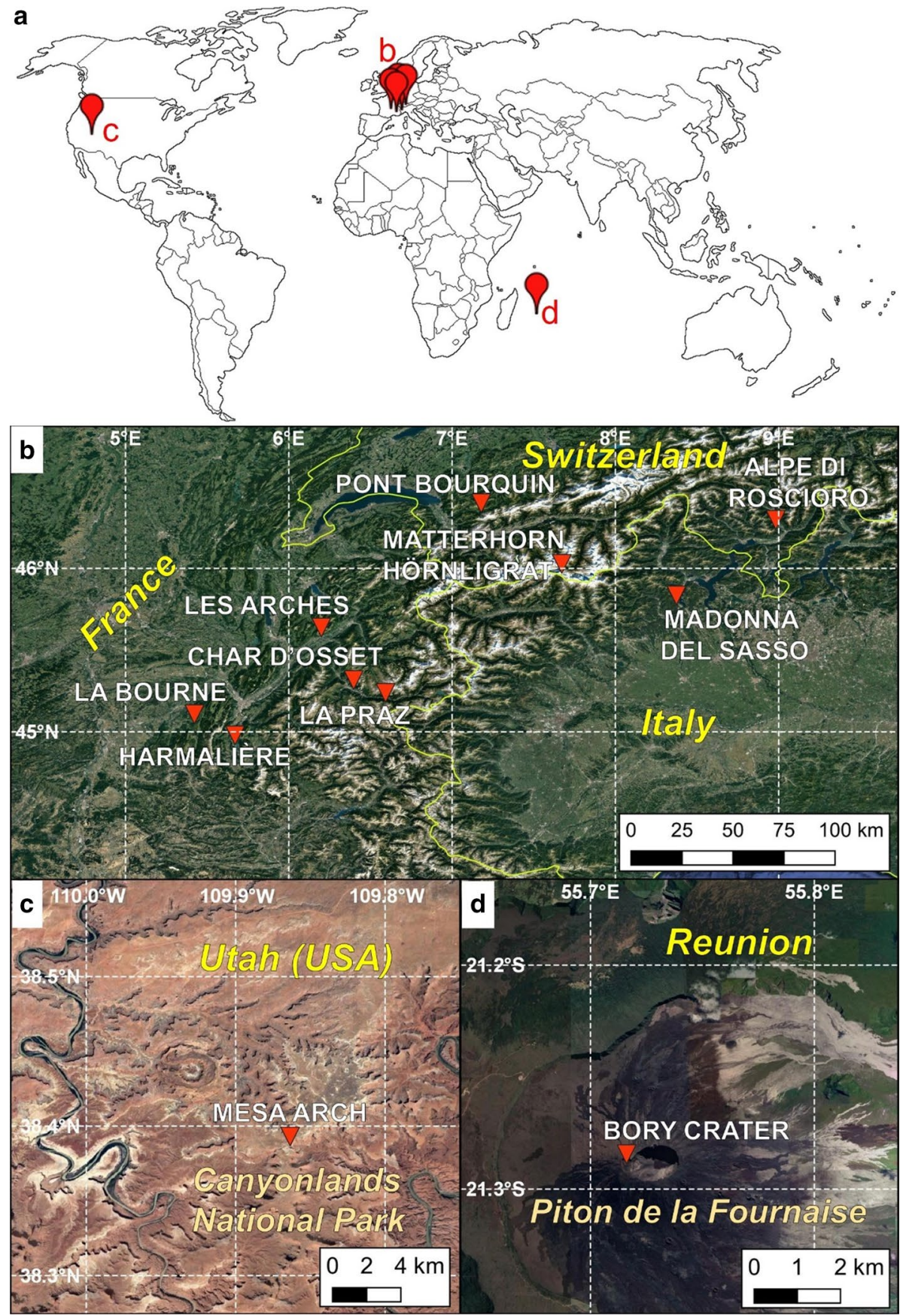

Fig. 3 a Location of the sites where long-term continuous seismic monitoring was conducted between 2012 and 2020 (references in Table 1). Red letters $\mathbf{b}$ to $\mathbf{d}$ refer to the locations shown in the detailed maps of the following subsections. b Unstable sites located in the Alps (France, Switzerland, Italy). c Mesa Arch (Utah, USA); d Bory Crater (Reunion Island) 


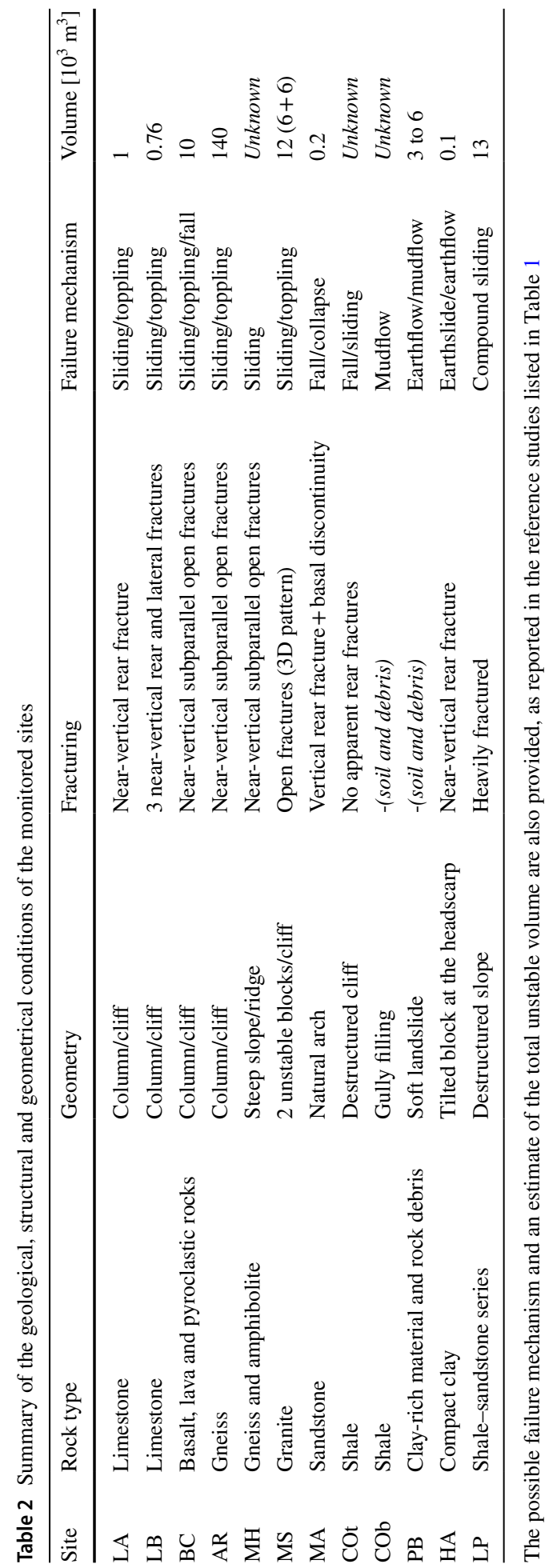




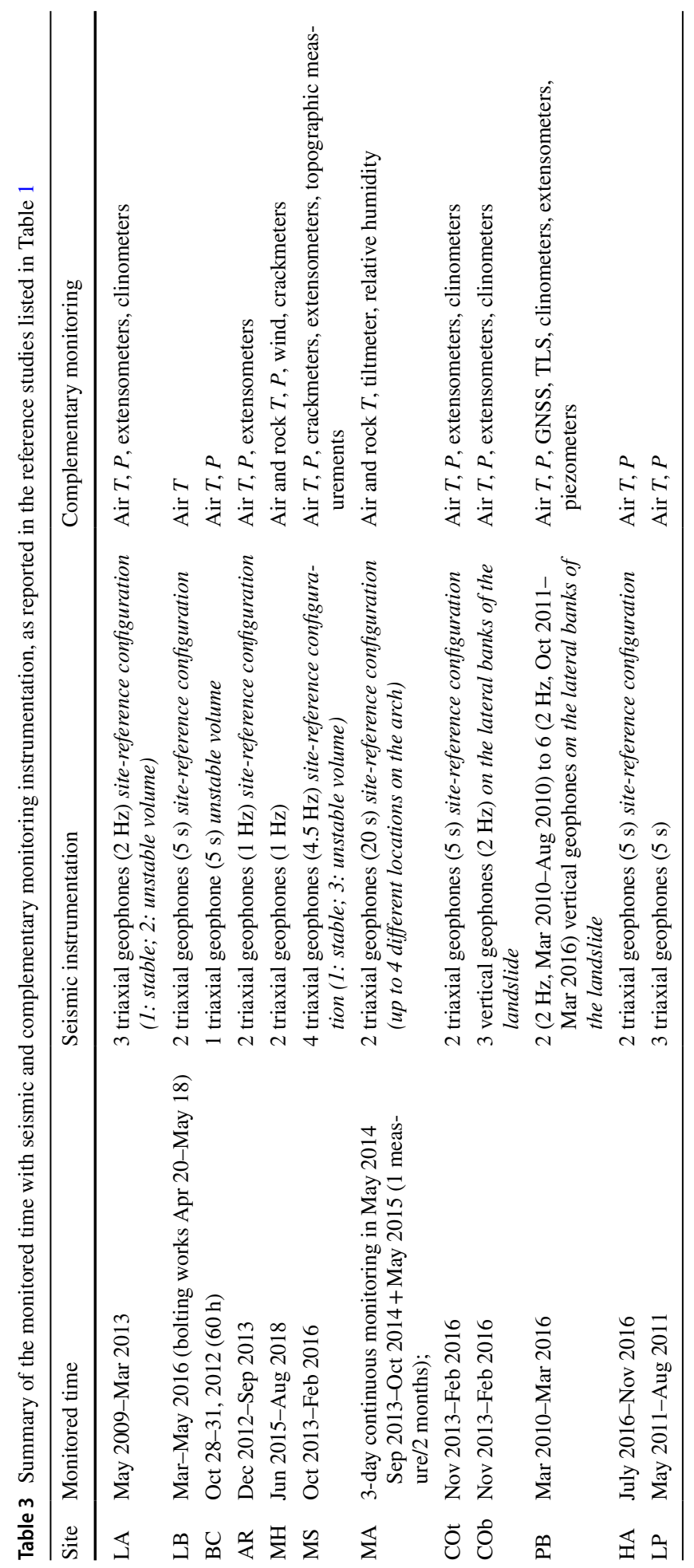


Fig. 3c) and a small lateral crater of the Dolomieu Crater of Piton de La Fournaise Volcano (Bory Crater, Reunion Island, Fig. 3d).

\subsection{Geological and Geometrical Characteristics}

The collected study sites show a wide variety of rock types, geometries and failure mechanisms. Eight sites (from LA to COt, in Table 2) are located in massive, poorly fractured rock masses. In particular, five sites exhibit a nearly 2D geometry, with rock columns or prisms separated from the stable mass by one or few long subparallel near-vertical fractures that can potentially generate sliding, toppling or falls of significant rock volumes. These sites include the limestone columns of Les Arches (LA), with a single rear fracture, and La Bourne (LB), with three near-vertical open fractures delimiting the unstable volume at the back and lateral sides. Column-type instabilities are also found at the basaltic near-vertical inner cliffs of Bory Crater (BC), delimited by a set of back parallel open fractures, at the near-vertical gneiss cliff of Alpe di Roscioro (AR), affected by near-vertical parallel open fractures, and at the steep slope of Matterhorn Hörnligrat ( $\mathrm{MH}$ ) made up of gneiss and amphibolites possibly dislocated by a similar fracture pattern. Madonna del Sasso (MS) site provides a peculiar 3D geometry, with the presence of two close unstable granitic compartments separated by fractures belonging to four different systems. The sandstone arch (MA) is a complex 3D object itself, whose stability is threatened by a vertical rear fracture and a basal discontinuity. The shale cliff of Char d'Osset (COt) regularly generates rock falls but does not show visible rear fractures on the plateau.

The remaining four sites stand on softer or destructured materials with respect to the previous rock instabilities. Three of these sites are settled in clay-rich materials. The middle part of the Char d'Osset slope $(\mathrm{COb})$ is a gully filled with destructured shale material, where debris flows are regularly generated. Pont Bourquin landslide (PB) can be classified as an earthflow to mudflow of clay-rich materials. The headscarp of the Harmalière landslide (HA) exhibits a cliff geometry with rear fractures, where clay blocks regularly slide along a slip plane. The last site, La Praz (LP), is a heavily fractured slope in a shale-sandstone series.

\subsection{Seismic Noise Parameters}

Continuous seismic monitoring at the different sites lasted from approximately 3 days (BC and MA) to several years (e.g., LA and PB, Table 3). For rock-type instabilities exhibiting visible rear open fractures, seismic instrumentation was generally deployed in site-reference configuration, having one or more sensors placed on the unstable compartment and a reference sensor located in a stable area. For COb and PB, pairs of vertical geophones were installed on the lateral banks of the active landslides. Complementary meteorological parameters were monitored at all sites, together with surface or internal displacements and fracture opening in several studies (Table 3).

Seismic noise parameters were derived from spectral analysis (resonance frequencies) and cross-correlation $(\mathrm{d} V / V)$. In this review, we mainly focused on the study of the first resonance frequency $(f 1)$, as higher modes have not been systematically measured at all sites. For two sites (MH and COt), the analysis of higher modes is, however, introduced to support the evaluation of temporal fluctuations. In particular, Weber et al. (2018) observed the third spectral peak $(f 3)$ of noise recordings to be more sensitive to $\mathrm{MH}$ site thermal variations, rather than the lower resonance frequencies, possibly due to 
the overlapping resonance effects of several unstable compartments of different size on the noise spectra. For COt site, Valentin (2018) detected the presence of anthropogenic disturbances in the frequency bands of $f l$ and $f 2$. Even if $f l$ temporal variations could be retrieved, $f 3$ showed a clearer correlation with the modification in external parameters and was consequently used for a more robust estimation of the delay in the seismic response.

The sites where resonance characteristics ( $f 1$ and vibration mode) and $\mathrm{d} V / V$ were measured are summarized in Table 4. For La Bourne (LB), $f 1$ was monitored on the unstable limestone block before, during and after bolting works that aimed at improving the site stability (Bottelin et al. 2017). In the following, only $f 1$ fluctuations driven by meteorological factors in the period before bolting will be analyzed.

Based on literature data, resonance frequency values were measured at ten sites, while cross-correlation was conducted at five sites. To enhance the comparison between the sites and deepen the characterization of $f 1$ and $\mathrm{d} V / V$ response to external factors, noise crosscorrelation was purposefully performed on Les Arches data for this study, following the same methodology applied to the other sites. (See Colombero et al. 2018 for the complete workflow.) In this way, complete information with both $f 1$ and $\mathrm{d} V / V$ computations is available at four sites (LA, MS, COt and HA, Fig. 4).

For all the rock columns or prisms and HA clayey block, $f 1$ is the resonance frequency of one or several compartments decoupled from the rock mass, with a bending mode almost perpendicular to the elongation of the rear fractures. At LP (high fracturing), $f 1$ was interpreted as resulting from a site effect (resonance of a soft layer over sound rock). No

Table 4 Average resonance frequency values $(f 1)$ for each monitored site, as reported in the reference studies of Table 1

\begin{tabular}{|c|c|c|c|}
\hline \multirow[t]{2}{*}{ Site } & \multicolumn{2}{|c|}{ Resonance frequency analysis (f1) } & \multirow{2}{*}{$\begin{array}{l}\text { Cross- } \\
\text { correlation } \\
\text { analysis } \\
(\mathrm{dV} / \mathrm{V})\end{array}$} \\
\hline & f1 & Vibration mode & \\
\hline LA & $6.3 \mathrm{~Hz}$ & Bending ( $\perp$ fracture) & $\begin{array}{l}\text { X (com- } \\
\text { puted } \\
\text { for this } \\
\text { study) }\end{array}$ \\
\hline LB & $9.5 \mathrm{~Hz}$ & Bending (nearly $\perp$ fracture) & - \\
\hline $\mathrm{BC}$ & $3 \mathrm{~Hz}$ & Bending ( $\perp$ fracture) & - \\
\hline AR & $3.5 \mathrm{~Hz}$ & Bending (nearly $\perp$ fracture) & - \\
\hline MH & $15 \mathrm{~Hz}(f 3)$ & $\begin{array}{l}\text { Overlapping effects of several } \\
\text { Unstable compartments }\end{array}$ & - \\
\hline MS & $2.9 \mathrm{~Hz}$ & Bending ( $\perp$ cliff elongation) & $\mathrm{X}$ \\
\hline MA & $3 \mathrm{~Hz}$ & Horizontal bending & - \\
\hline $\mathrm{COt}$ & $7.1 \mathrm{~Hz}$ & Bending ( $\perp$ cliff edge) & $X$ \\
\hline $\mathrm{COb}$ & no data & - & $\mathrm{X}$ \\
\hline PB & no data & - & $X$ \\
\hline HA & $8.5 \mathrm{~Hz}$ & Bending $(\perp$ fracture $)$ & $\mathrm{X}$ \\
\hline LP & $5.7 \mathrm{~Hz}$ & - & - \\
\hline
\end{tabular}

An indication of the vibration mode type and direction ( $\perp$ : perpendicular to rear fracture elongation) is provided for the sites on which ground motion analysis and/or numerical modeling were conducted. $\mathrm{X}$ symbols in the last column refer to sites at which cross-correlation analysis was performed and $\mathrm{d} V / V$ fluctuations were retrieved 


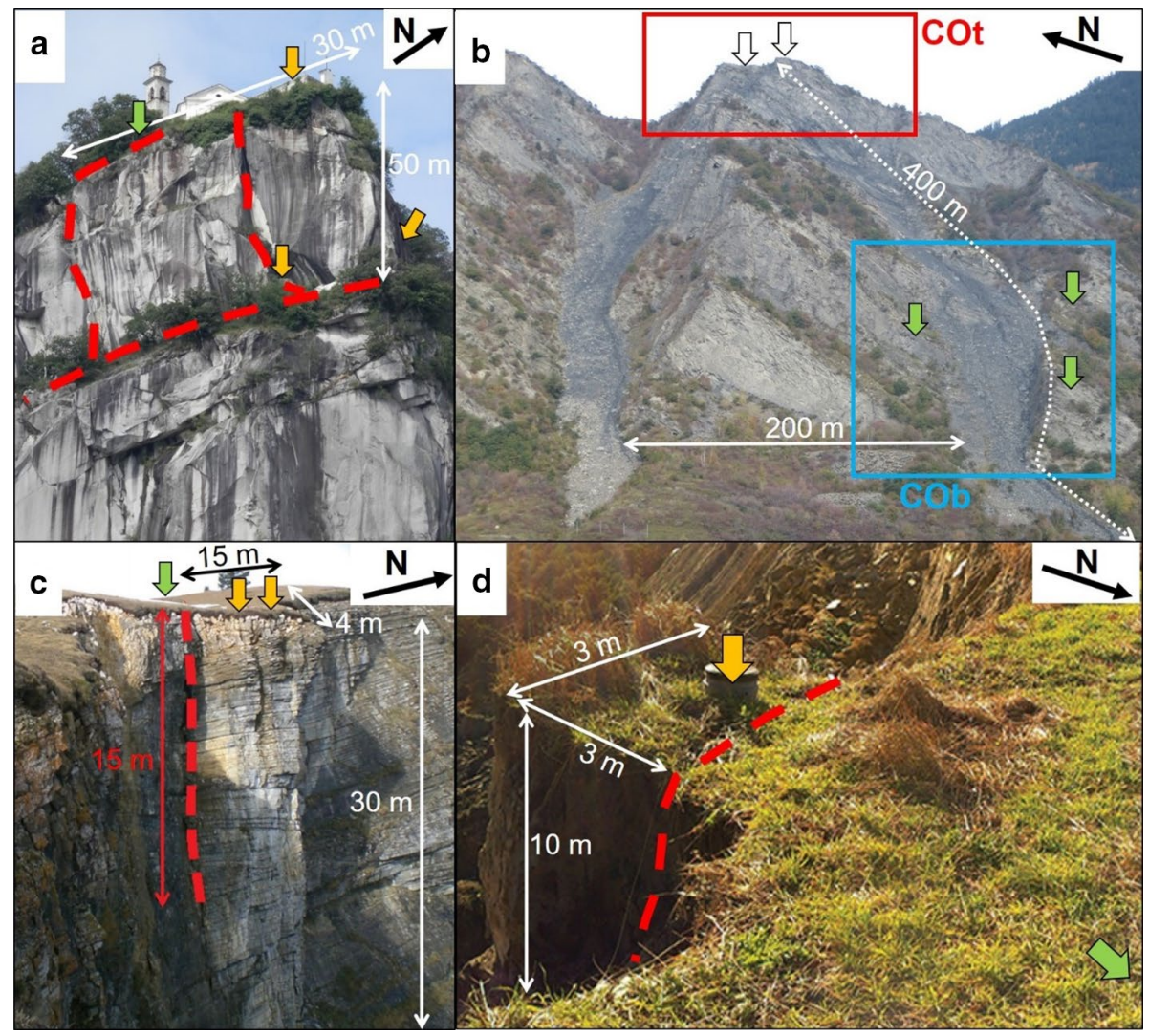

Fig. 4 Images of the four sites with available $f 1$ and $\mathrm{d} V / V$ data. a Madonna del Sasso cliff (MS). b Char d'Osset top site (COt, red rectangle). For COb (blue rectangle) only $\mathrm{d} V / V$ data are available. c Les Arches limestone column (LA). d Harmalière clayey block before collapse (HA). In all sections, red dashed lines highlight the location of the main open fractures. Colored arrows approximately mark the location of ambient seismic noise stations (green: reference station on stable sector, yellow: unstable sector, white: COt stations at the cliff edge)

resonance frequencies were measured at $\mathrm{COb}$ and $\mathrm{PB}$ because the sensors were deployed on the stable zone. Depending on the monitored time (Table 3), daily or seasonal variations of the seismic parameters as a function of the meteorological factors could be established.

\section{Analysis of Reversible Modifications}

Reversible modifications in $f 1$ and $\mathrm{d} V / V$ collected from the reference case studies showed a wide variety of magnitudes at the daily and seasonal scale. Both positive and negative correlations with air temperature and rainfall trends were highlighted. In many cases, the response of $f l$ and $\mathrm{d} V / V$ factors to external factors was found to have a delay on both daily and seasonal cycles, while it was immediate for other sites. We present first in Fig. 5 to Fig. 8 the results obtained at the four sites (MS, COt, LA and HA, Fig. 4) for which both 

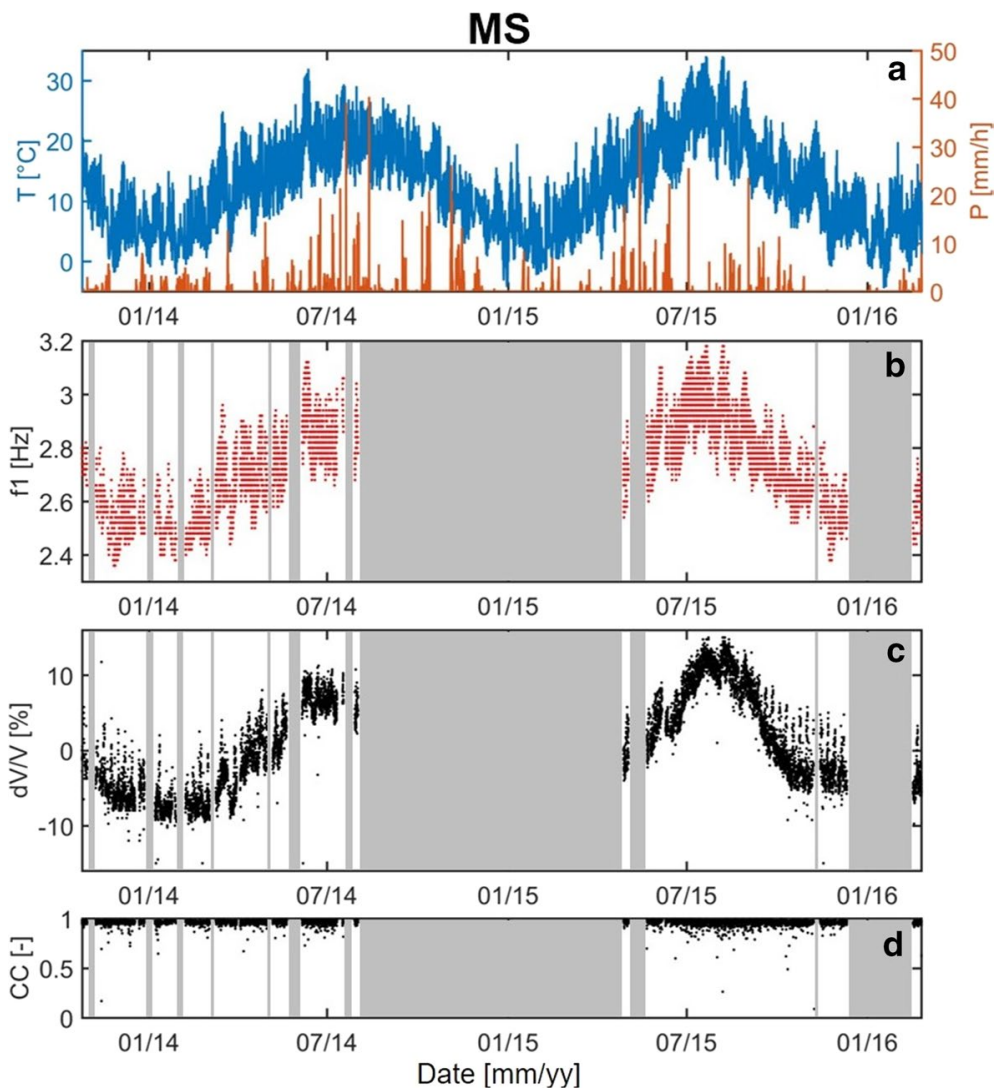

Fig. 5 Madonna del Sasso (MS) site. a Air temperature and hourly rainfall amounts. b $f 1$ values recorded on the main unstable compartment (from Colombero et al. 2018). c Hourly velocity changes from site-reference cross-correlation of the $\mathrm{N}$ components (2-4 Hz frequency band, from Colombero et al. 2018). d Related correlation coefficients. Gray windows are overlapped to periods with unavailable monitoring data

$f 1$ and $\mathrm{d} V / V$ data are available. In the second part of the section, the results of all sites are summarized and analyzed.

\subsection{Detailed Analysis at Four Sites with Both $\mathrm{f1}$ and dV/V Data}

At Madonna del Sasso (MS, Fig. 4a), data recorded on one of the two unstable granitic compartments are clearly controlled by the temperature trend at both the daily and seasonal scales (Fig. 5, zoomed-in time windows available in Colombero et al. 2018 to better visualize daily variations). A positive correlation between $f 1-\mathrm{d} V / V$ and $T$ was established over the whole monitored period (Colombero et al. 2018). No significant delay ( $<1 \mathrm{~h}$ for the daily trends, $<1 \mathrm{~d}$ for the seasonal fluctuations) was found between $f 1-\mathrm{d} V / V$ results and $T$. At this site, precipitation amounts do not seem to affect $f 1$ and $\mathrm{d} V / V$ fluctuations.

More complex responses in the seismic parameters are highlighted at the other sites. The Char d'Osset cliff (COt, Fig. 4b) also shows positive correlation between seismic parameters and temperature data (Valentin 2018). However, the response of both $f 1$ (Fig. 6b) and dV/V (Fig. 6d) to $T$ variations (Fig. 6a) is not immediate as observed for MS. 


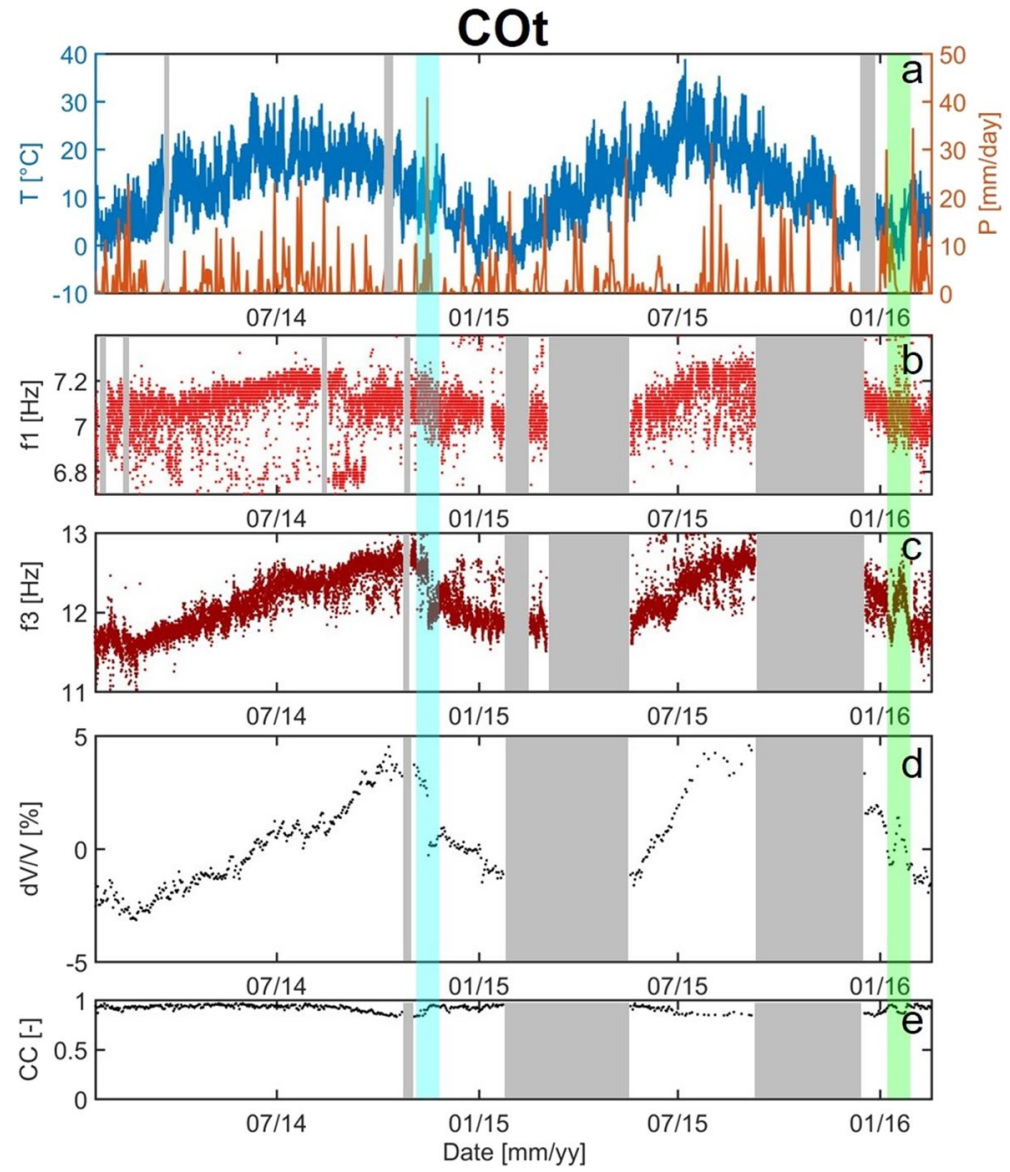

Fig. 6 Char d'Osset top site (COt). a Air temperature and daily rainfall amounts. b $f 1$ and c $f 3$ values recorded at the headscarp (from Valentin 2018). d Daily velocity changes from site-reference cross-correlation of the $\mathrm{V}$ components (10-12 Hz frequency band, from Valentin 2018). e Related correlation coefficients. Gray windows are overlapped to periods with unavailable monitoring data. The blue and green windows highlight periods in which seismic parameters are not correlated with temperature fluctuations

Since the quality of $f l$ data was partially affected by the presence of overlapping anthropic disturbances in the same frequency band, $f 3$ variations are supplementary shown in Fig. 6c. Valentin (2018) estimated the delay of $f 3$ and $\mathrm{d} V / V$ to $T$ at the seasonal scale to be 58 and 63 days, respectively. In the same work, for both seismic parameters a delay was also noticed at the daily scale and estimated at $23 \mathrm{~h}$ for the resonance frequencies (i.e., f3) and at $18 \mathrm{~h}$ for $\mathrm{d} V / V$ response to temperature cycles.

Beside the temperature control, on shorter localized time windows, seismic parameters showed correlation to heavy rainfall amounts. As an example, a clear drop in $\mathrm{d} V / V$ is observed in Fig. 6d immediately after the highest rainfall peak occurred in December 2015 ( $40 \mathrm{~mm} /$ day, highlighted by a blue window in Fig. 6a), suggesting additional water control on the reversible fluctuations. A coherent drop, uncorrelated with the temperature trend, is found at the same time for $f 3$ (Fig. 6c), less visible for $f 1$ (Fig. 6b). Another clear 
anomaly in the temperature-controlled trend is depicted in January 2016 (green window in Fig. 6). While temperature decreasing under $0{ }^{\circ} \mathrm{C}$ after a period of intense rainfalls (Fig. 6a), $f 3$ and $\mathrm{d} V / V$ data conversely locally increase (negative correlation). A significant influence of water precipitation and seepage must therefore be considered in addition to temperature as a control on the site response.

Contrarily to MS and COt, negative correlation between $f 1$ and temperature was found at Les Arches (LA, Fig. 4c) at the seasonal scale (Bottelin et al. 2013b). Three stations were deployed at this site, having two sensors placed on the top of the potentially unstable compartment and one reference station located on the stable cliff, at a distance of approximately $17 \mathrm{~m}$ from the rear open fracture isolating the limestone column. Both stations located on the column exhibited the same $f l$ values and related variations, while no spectral peaks were detected on the reference one. During winter months (e.g., mid-November 2010-late April 2011) a significant increase (+300\%) in $f 1$ values was detected (Fig. $7 \mathrm{~b})$. Also outside this period, $f l$ and $T$ have a negative correlation at the seasonal scale $(f l$ seasonal trend is decreasing while $T$ is increasing, Fig. 7c and Appendix), with more than 2 months of delay, as reported by Bottelin et al. (2013b). At the daily scale, $f 1$ and $T$ have conversely a positive correlation with a few hours of delay, as shown in the zoom of Fig. 7c and reported in the Appendix.

The response of $\mathrm{d} V / V$ is even more complex. A clear temperature control on $\mathrm{d} V / V$ fluctuations is highlighted only in the cross-correlation of noise recorded by the two stations located on the unstable column, in a specific frequency band (6-8 Hz, i.e., overlapping the resonance frequency, Fig. 7d) and for the non-freezing period. During these months, $\mathrm{d} V / V$ response showed the same negative correlation at the seasonal scale and positive correlation at the daily scale with temperature as detected by $f l$ fluctuations, with comparable delays ( $2 \mathrm{~h}$ and 68 days, respectively, details about delay computations are reported in the Appendix). Conversely, very high CC values are obtained during winter months (Fig. 7e, mid-November 2010-late April 2011), but only slight changes in $\mathrm{d} V / V$ values $(<2 \%)$ are detected in this window. At the end of April, a clear change in $\mathrm{d} V / V$ is observed, perfectly matching with $f l$ fluctuations. The results are, however, highly different when cross-correlating noise recordings from one of the stations located on the unstable compartment and the stable reference one (Fig. 7f). In this case, low correlation is always obtained outside the winter period for all the analyzed $2 \mathrm{~Hz}$ frequency bands $(2-30 \mathrm{~Hz})$. High $\mathrm{CC}$ values are found only during winter months (Fig. $7 \mathrm{~g}$, same frequency band of Fig. 7e) with associated low $\mathrm{d} V / V$ fluctuations. This general winter trend is interrupted by localized $\mathrm{d} V / V$ and CC drops, mirroring the minor drops in $f l$ detected over the same period during or immediately after periods in which air temperature rises above $0{ }^{\circ} \mathrm{C}$. At the end of April, a significant drop in $\mathrm{CC}$ values occurs and no coherent $\mathrm{d} V / V$ fluctuations can be extracted from crosscorrelation in site-reference configuration for the following period in any frequency band.

Finally, the seismic noise parameters were extracted between two stations located across a rear fracture of the Harmalière headscarp (HA, Fig. 4d) during the four months preceding the block failure, which occurred in late November 2016 (Fiolleau et al. 2020). An opposite trend between decreasing temperature and increasing $f 1$ values is found at the seasonal scale, comparing Fig. 8a and Fig. 8b. Nevertheless, the response of $\mathrm{d} V / V$ over the first 2.5 months does not show the same trend (Fig. 8d) and velocity fluctuations are limited $( \pm 2 \%)$ compared to those of $f 1( \pm 12 \%)$. Negative correlation between $f l$ and $T$ was also found at the daily scale (zoomed-in time windows available in Fiolleau et al. 2020) with a progressive increase in delay from 4 to $10 \mathrm{~h}$ in the period between August and midOctober 2016 (Fig. 8c). During the last 40 days of monitoring before the block failure, the delay becomes unstable, probably due to the increasing number of microearthquakes 

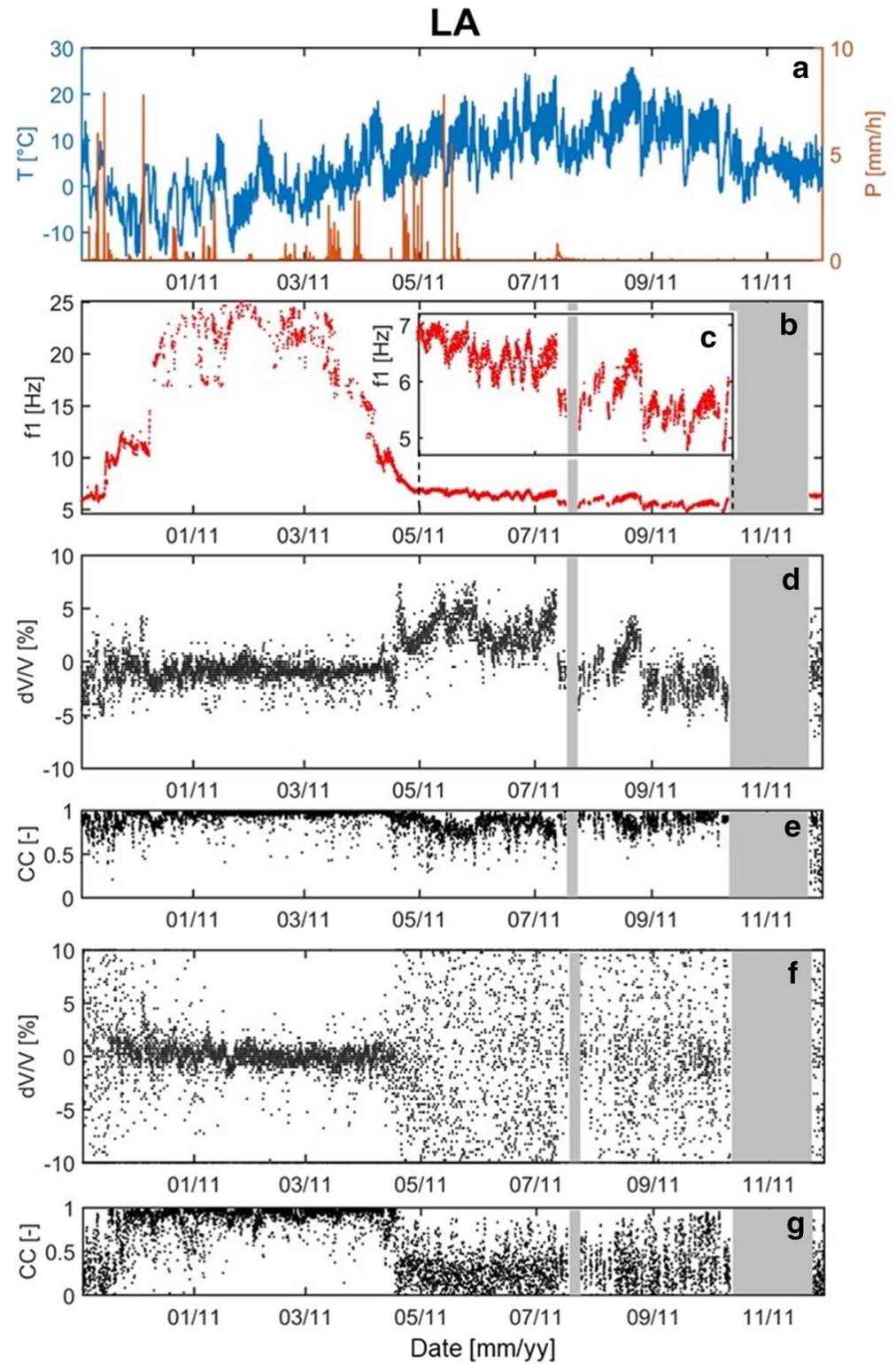

Fig. 7 Les Arches (LA) site. a Air temperature and hourly rainfall amounts. b $f 1$ values recorded on the unstable compartment (see Bottelin et al. 2013b for a longer time period). c Zoom on $f 1$ trend outside the freezing period. d Hourly velocity changes from cross-correlation of the $\mathrm{V}$ components of the two stations on the unstable compartment (6-8 Hz frequency band). e Related correlation coefficients. f Hourly velocity changes from site-reference cross-correlation of the $\mathrm{V}$ components (6-8 Hz frequency band). $\mathrm{g}$ Related correlation coefficients. Gray windows show periods with unavailable monitoring data

interfering with seismic noise recordings and $f 1$ measurement (Fiolleau et al. 2020). In the same period, $\mathrm{d} V / V$ becomes increasingly variable and associated $\mathrm{CC}$ values decrease. In the days prior to failure, there is a decrease in $f 1$ not corresponding to increasing $T$ and thus 


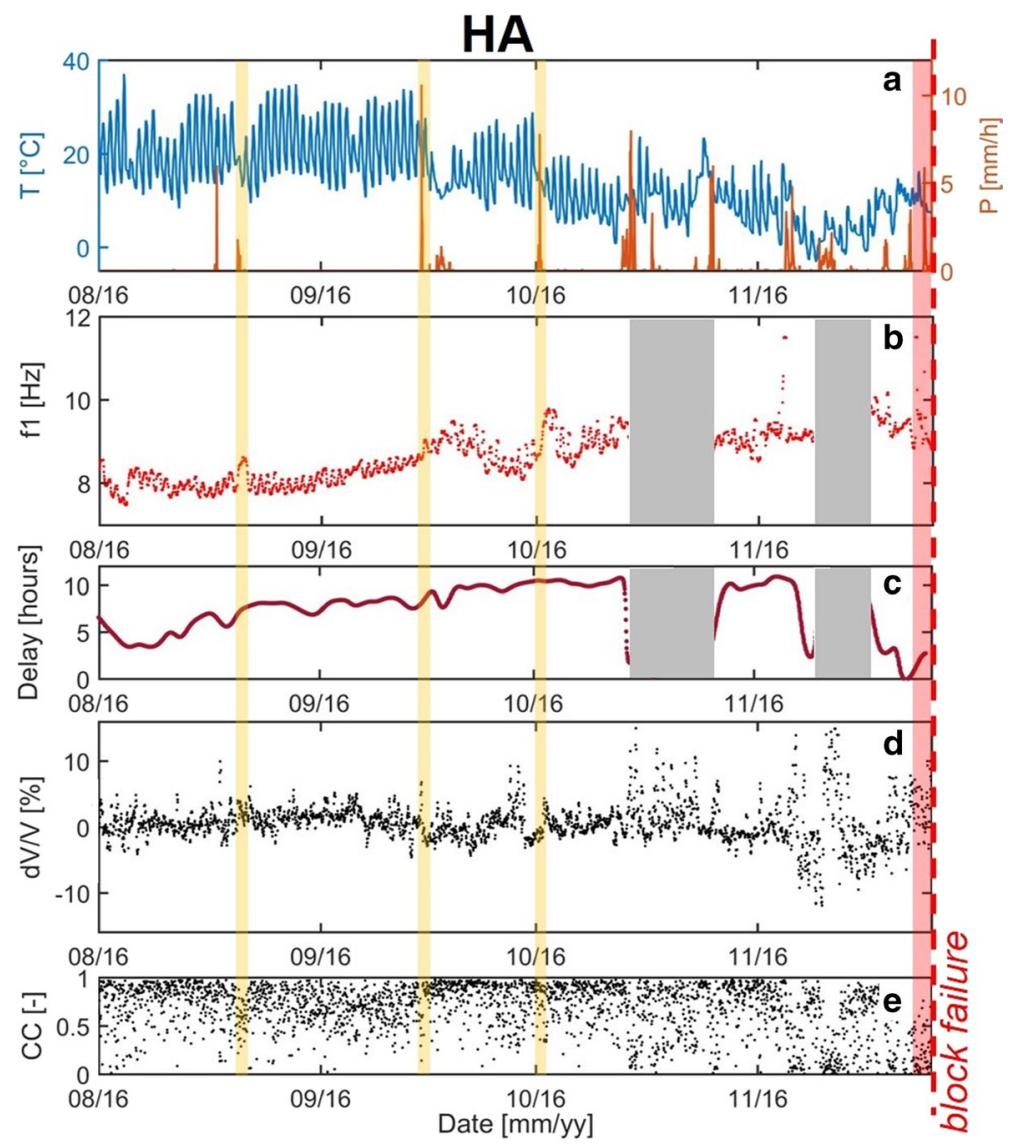

Fig. 8 Harmalière (HA) site. a Air temperature and hourly rainfall amounts. b $f 1$ values recorded on the unstable compartment (from Fiolleau et al. 2020). c Delay of $f 1$ response to $T$ variations at the daily scale. d Hourly velocity changes from site-reference cross-correlation of the V components $(8-10 \mathrm{~Hz}$ frequency band, from Fiolleau et al. 2020). e Related correlation coefficients. Yellow windows highlight periods in which a positive correlation between $P$ peaks and $f 1$ is found. Gray windows show periods with unavailable $f 1$ data. The time window preceding the block failure ( $f 1$ irreversible drop) is highlighted in red

disclosing irreversible modifications (Fig. 8b, red window). Contrary to COt site, precipitation peaks (20/08/2016, 17/09/2016 and 01/10/2016, yellow windows in Fig. 8) induced a reversible increase in $f 1$ and $\mathrm{d} V / V$ at $\mathrm{HA}$, with variations of up to $+10 \%$ for $f 1$ independently from the temperature trend. Rainfall and water seepage at this site seem therefore to induce a positive correlation in the recorded seismic parameters.

\subsection{Synthesis for all Sites}

Daily and seasonal variations of the seismic parameters are summarized for all case studies, considering periods with $T>0{ }^{\circ} \mathrm{C}$ (Figs. 9 and 10), $T<0{ }^{\circ} \mathrm{C}$ (Table 5) and relation to $P$ (Table 6). 

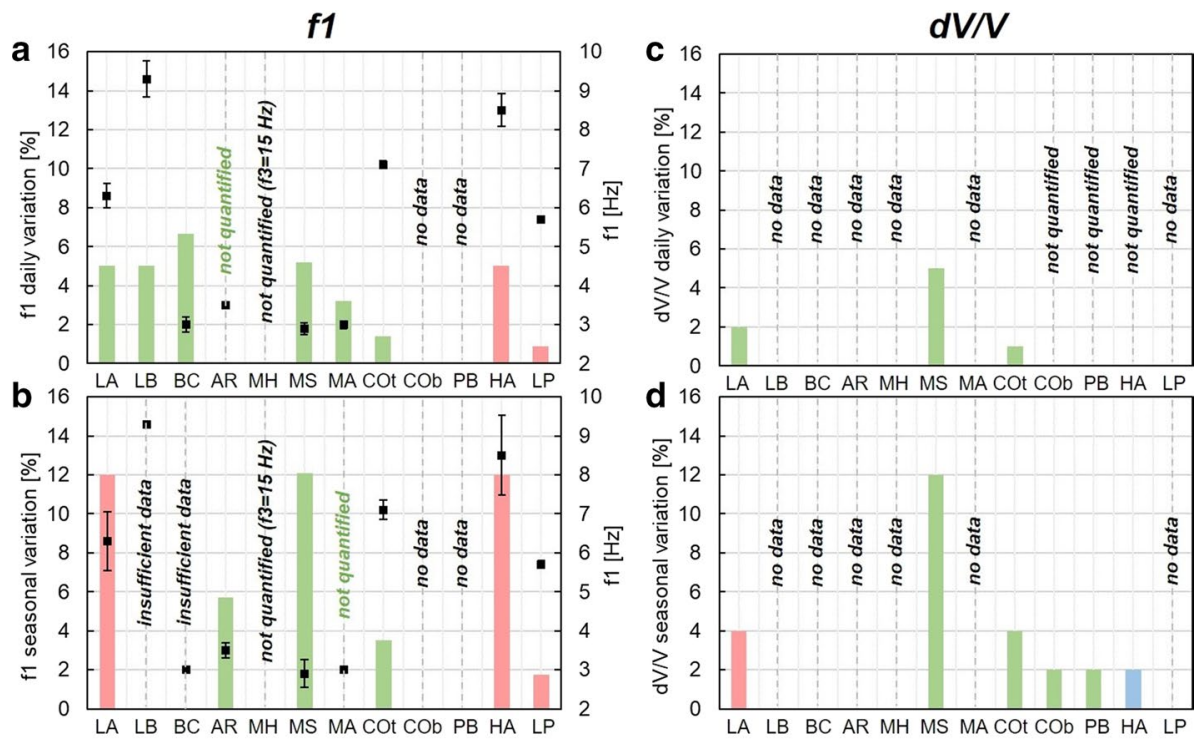

Fig. 9 Resonance frequency $(f 1)$ variations and velocity changes $(\mathrm{d} V / V)$ for all the case studies during periods with air temperature $T$ higher than $0{ }^{\circ} \mathrm{C}$. $\mathbf{a}$ and $\mathbf{b}$ : $f 1$ values and variations at the daily and seasonal scale, respectively. The average frequency and the variations (right axis) are shown with black squares and vertical black bars (where visible). The percentage of variation from the average value is also displayed with colored bars (left axis). $\mathbf{c}$ and $\mathbf{d}: \mathrm{d} V / V$ variations at the daily and seasonal scale, respectively. Green rectangles: positive correlation with $T$. Red rectangles: negative correlation with $T$. Blue rectangles: no correlation with $T$. No data: no $f 1$ or $\mathrm{d} V / V$ data for evaluating the variations. Insufficient data: $f 1$ or $\mathrm{d} V / V$ data are computed on a time window which is too short to evaluate the seismic parameter variations. Not quantified: $f 1$ and/or $\mathrm{d} V / V$ data are computed in the original work, but the temporal variations are not quantified (for some sites positive or negative correlation with $T>0{ }^{\circ} \mathrm{C}$ is, however, indicated by the authors)
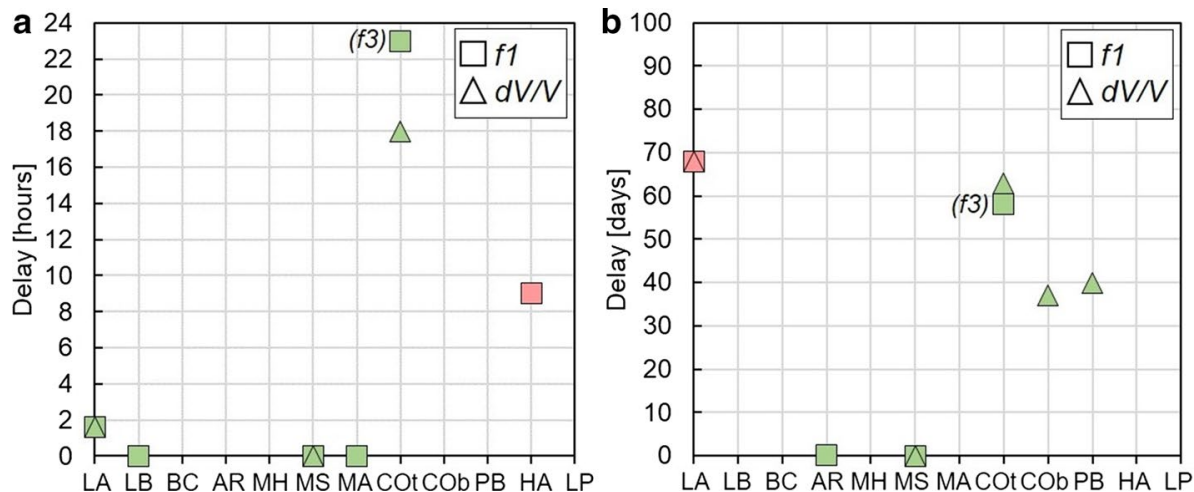

Fig. 10 Delay in the response of $f 1$ (squares) and $\mathrm{d} V / V$ (triangles) to temperature, during periods with air temperature $T$ higher than $0{ }^{\circ} \mathrm{C}$, for sites with available reference information (for COt the delays are computed on $f 3$ data). a Daily scale. b Seasonal scale. Green markers: positive correlation with $T$. Red markers: negative correlation with $T$ 
Table 5 Resonance frequency $(f 1)$ variations and velocity changes $(\mathrm{d} V / V)$ for all the case studies during periods with air temperature $T$ lower than $0{ }^{\circ} \mathrm{C}$

\begin{tabular}{|c|c|c|}
\hline Site & f1 & dV/V \\
\hline LA & Up to $+300 \%$ & No change (?) \\
\hline LB & Insufficient data & No data \\
\hline BC & Insufficient data & No data \\
\hline AR & $\begin{array}{c}\text { Not quantified } \\
\text { Delay= } 4 \text { d }\end{array}$ & No data \\
\hline MH & Around $+230 \%$ & No data \\
\hline MS & No change & No change \\
\hline MA & Not quantified & No data \\
\hline COt & Up to +8\% (f3) & Up to +2.5\% \\
\hline COb & No data & No change \\
\hline PB & No data & No change \\
\hline HA & Insufficient data & Insufficient data \\
\hline LP & No data & No data \\
\hline
\end{tabular}

Red cells: negative correlation with $T$. Gray cells: no change with respect to the trend detected when $T>0{ }^{\circ} \mathrm{C}$. No data: no $f 1$ or $\mathrm{d} V / V$ data for evaluating the variations. Insufficient data: $f 1$ or $\mathrm{d} V / V$ data are computed on a time window which is too short to evaluate the seismic parameter variations while $T<0{ }^{\circ} \mathrm{C}$. Not quantified: $f 1$ and/or $\mathrm{d} V / V$ data are computed in the original work in periods with $T<0{ }^{\circ} \mathrm{C}$, but the related temporal variations are not quantified by the original authors

Table 6 Resonance frequency $(f 1)$ variations and velocity changes $(\mathrm{d} V / V)$ for all the case studies during or immediately after precipitation $(P)$

\begin{tabular}{|c|c|c|}
\hline Site & f1 & dVN \\
\hline LA & No change & No change \\
\hline LB & Insufficient data & No data \\
\hline BC & Insufficient data & No data \\
\hline AR & Around $-4 \%$ & No data \\
\hline MH & Not quantified & No data \\
\hline MS & No change & No change \\
\hline MA & No change & No data \\
\hline COt & $-4 \%$ (f3) & $-2.5 \%$ \\
\hline COb & No data & $-1.5 \%$ \\
\hline PB & No data & $\begin{array}{l}\text { Up to }-4 \% \\
\text { Delay= } 2-7 \mathrm{~d}\end{array}$ \\
\hline HA & Up to $+12 \%$ & Up to $+10 \%$ \\
\hline LP & No change & No data \\
\hline
\end{tabular}

Green cells: positive correlation with $P$. Red cells: negative correlation with $P$. Gray cells: no change with respect to the trend detected when $T>0{ }^{\circ} \mathrm{C}$. No data: no $f 1$ or $\mathrm{d} V / V$ data for evaluating the variations. Insufficient data: $f 1$ or $\mathrm{d} V / V$ data are computed on a time window which is too short to evaluate the seismic parameter variations during rainfalls. Not quantified: $f 1$ and/or $\mathrm{d} V / V$ data are computed in the original work in periods with rainfalls, but the related temporal variations are not quantified by the original authors 
The quantified variations are plotted in the graphs as originally reported in the reference works of Table 1. In Fig. 9, beside the average values and the associated vertical bars indicating the range of fluctuation, variations of $f 1$ are also reported as percentage of variation from the average value of the whole monitored period with vertical colored bars, allowing direct comparison with $\mathrm{d} V / V$ variation ranges. Positive correlations of the seismic parameter variations with $T>0{ }^{\circ} \mathrm{C}$ (Fig. 9), $T<0{ }^{\circ} \mathrm{C}$ (Table 5) and $P$ (Table 6) are reported in green, while negative correlations are highlighted in red. If $f 1$ or $\mathrm{d} V / V$ data were computed in the original works, but the related temporal variations were not evaluated by the authors, the related site information is classified as 'not quantified.' For some of these sites, the original authors, however, concluded that there was a positive or negative correlation with the considered meteorological parameters. These labels are colored in green (positive correlation) and red (negative correlation). The labels 'no data' and 'insufficient data' refer to the sites for which $f l$ or $\mathrm{d} V / V$ were not computed (see Table 4), or the monitored time window was insufficient to compute the related variations (i.e., too short to compute seasonal variations), respectively.

At all sites with available information, $f 1$ and $\mathrm{d} V / V$ exhibit a clear correlation with $T>0{ }^{\circ} \mathrm{C}$, except the $\mathrm{d} V / V$ seasonal fluctuation at HA site (in blue in Fig. 9). In the case that the temperature-related delay in the seismic response was provided in the original works (Table 1), its value is shown in Fig. 10 with the same color code.

At the daily scale (Fig. 8a and c; Fig. 10a), the seismic response to temperature variations is positive for all the hard rock sites with a limited number of rear fractures (from LA to COt), with delays ranging from 0 (e.g., LB, MS, MA) to 18-23 h (e.g., COt). By contrast, at the same scale of observation, $f l$ response is negatively correlated with $T$ for the heavily fractured slope of La Praz (LP) and the clayey block of Harmalière (HA). Similar conclusions can be applied to the seasonal scale (Fig. $8 \mathrm{~b}$ and d), with the exception of Les Arches (LA) column. At this site, negative correlation with $T$ is found at the seasonal scale for both $f 1$ and $\mathrm{d} V / V$ with a considerable delay of more than 2 months (Fig. 10b and Appendix).

Different responses to $T<0{ }^{\circ} \mathrm{C}$ are observed (Table 5). In particular, $f 1$ and $\mathrm{d} V / V$ recorded at MS do not deviate from the $T$-driven variations detected during periods with $T>0{ }^{\circ} \mathrm{C}$ (Fig. 5b). A clear increase in $f 1(+300 \%)$ is conversely recorded at LA (Fig. 7b). No similar increase is found from $\mathrm{d} V / V$ analyses. At $\mathrm{MH}, f 3$ increases up to $+230 \%$, while $T<0{ }^{\circ} \mathrm{C}$. At COt, temperature decrease below $0{ }^{\circ} \mathrm{C}$ is accompanied by a simultaneous increase in both $f 1$ (up to $+7 \%$ ) and $\mathrm{d} V / V$ (up to $+2.5 \%$ ). Significant increases in $f 1$ values are reported in the literature for other several sites (AR, MA), while $T<0{ }^{\circ} \mathrm{C}$, even if the amount of variation was not quantified by the original authors (Table 1).

Daily and seasonal $f l$ and $\mathrm{d} V / V$ trends were often observed to have a negative correlation with $P$ (Table 6). A decrease in $f l$ was observed at AR during spring months (around $-4 \%$ ), not correlated with $T$ fluctuations. In addition, $f 1$ and $\mathrm{d} V / V$ were found in negative correlation with $P$ at other three sites (COb, COt, $\mathrm{PB}$ ) during short time windows localized during and immediately after the most intense rainfalls. Though all these sites are characterized by clay-rich materials, the clayey block of HA conversely showed a positive correlation with $P$. No $P$ effect was observed at four rock sites (LA, MS, MA, LP). 


\section{Driving Mechanisms}

From the literature studies of Table 1, we have identified six driving mechanisms, which have been proposed by the original authors to explain the reversible variations on the basis of the seismic observations coupled with monitored site displacements (Table 3). Some of the mechanisms have been further confirmed by thermomechanical numerical modeling of the long-term behavior (Bottelin et al. 2013b; Fiolleau et al. 2020).

The first three mechanisms result from the effect of temperature changes on fractures (fracture effect, $\mathrm{FE}$ ), at the ground surface (surface effect, $\mathrm{SE}$ ) and in the bulk (bulk effect, BE). In two other mechanisms, water play a role, alone (water effect, WE) or associated with temperature (ice effect, IE). The last identified mechanism is linked to the

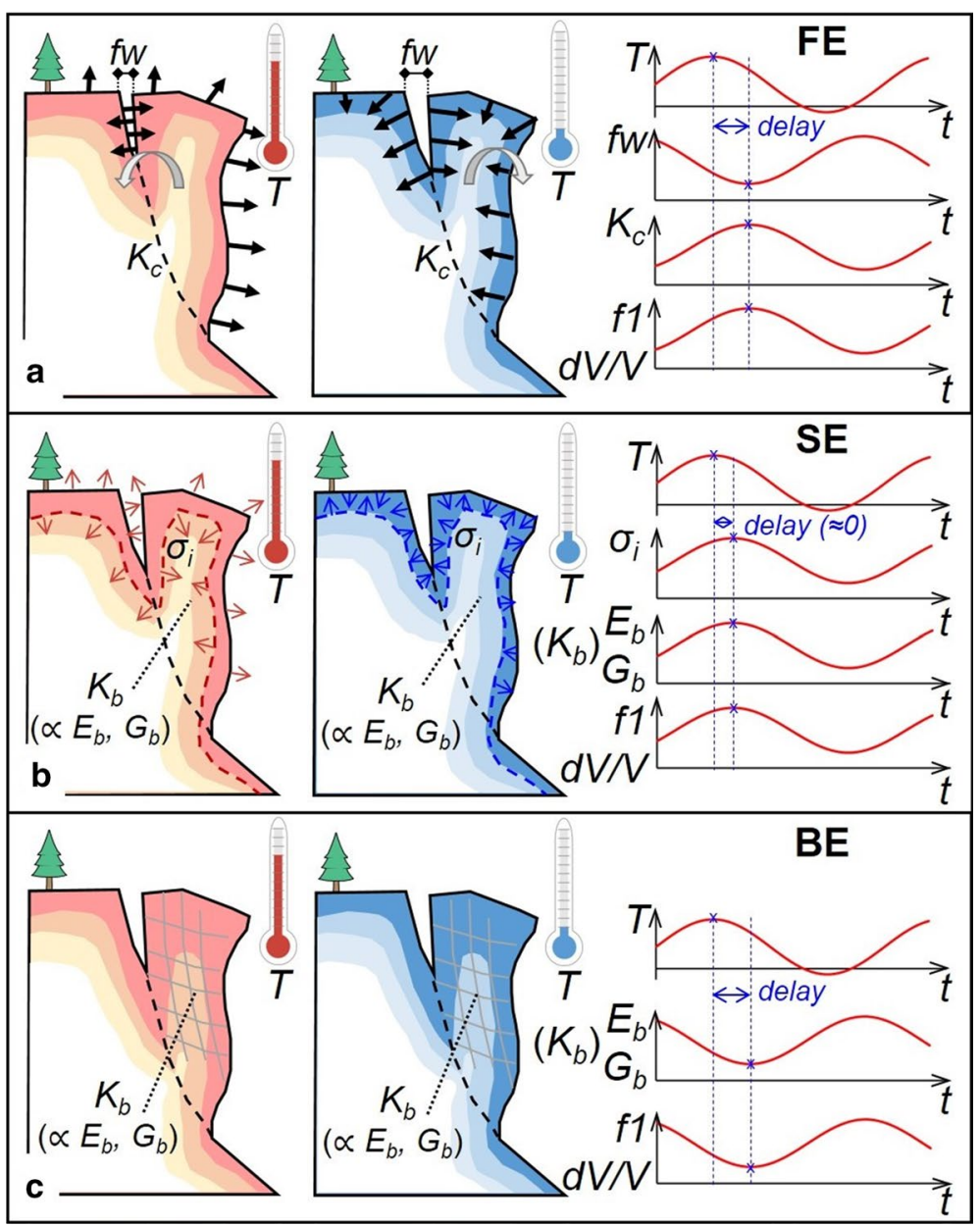

Fig. 11 Temperature-driven mechanisms causing $f 1$ and/or $\mathrm{d} V / V$ reversible variations: a fracture effect; b surface effect; c bulk effect. $T$ : air temperature, fw: fracture width, $K_{c}$ : contact stiffness, $K_{b}$ : bulk stiffness, $E_{b}$ : bulk Young's modulus; $G_{b}$ : bulk shear modulus; $\sigma_{i}$ : internal stresses, $t$ : time (daily and/or seasonal scale) 


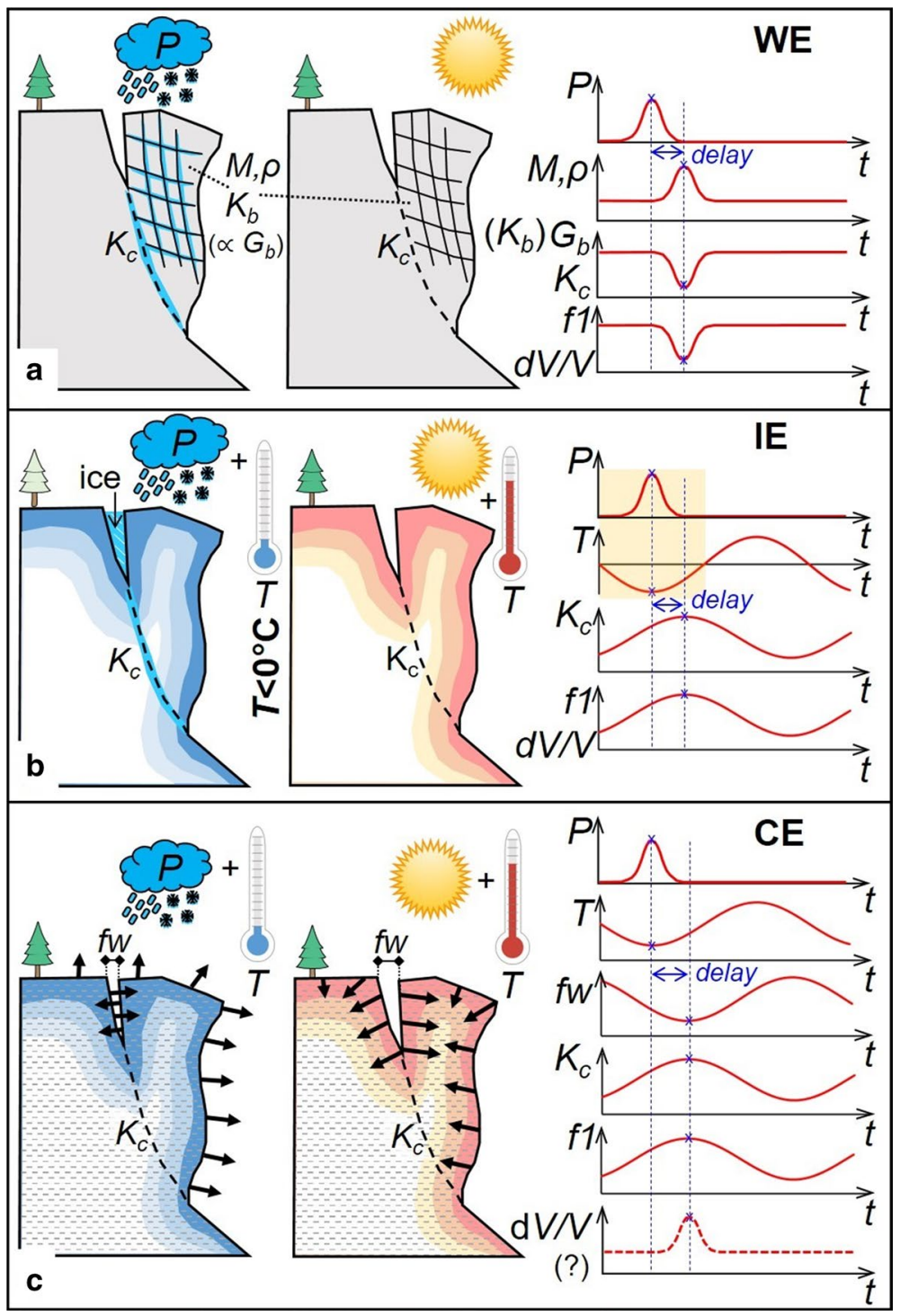

Fig. 12 Precipitation-driven and temperature-precipitation-driven mechanisms causing $f 1$ and/or $\mathrm{d} V / V$ reversible variations: a water effect; $\mathbf{b}$ ice effect; $\mathbf{c}$ clay effect. $T$ : air temperature, $P$ : precipitation, $K_{c}$ : contact stiffness, $K_{b}$ : bulk stiffness, $G_{b}$ : bulk shear modulus, $M$ : mass, $\rho$ : density, $f w$ : fracture width, $t$ : time (daily and/or seasonal scale)

hydro-thermomechanical behavior of clay (clay effect, $\mathrm{CE}$ ). In this section, we first critically analyze the six driving mechanisms to clarify their role and evaluate their significance. Figures 11 and 12 present diagrams qualitatively summarizing the effect of meteorological factors on a potentially unstable compartment, as well as illustrative time curves of parameter variations (at daily and/or seasonal scale), for all the identified mechanisms. A synthesis is made at the end of the section. 


\subsection{Fracture Effect (FE)}

Air temperature fluctuations induce rock mass thermal expansion or contraction (Fig. 11a). With increasing $T$, thermal dilation (with or without delay) may consequently cause closing of fractures and microcracks (reduction in fracture width $f w$ ) and a relative increase in the fracture contact stiffness $\left(K_{c}\right)$. Considering Eq. 1, an increase in $f l$ consequently takes place. With decreasing $T$, the opposite process takes place: Rock mass thermal contraction induces fracture opening (increase in $f w$ ) and decoupling of the unstable sector (reduction in $K_{c}$ ) with decreasing $f 1$ values. Since $\mathrm{d} V / V$ retrieved in the frequency band of the resonance frequency (fundamental or higher modes, e.g., MS and COt) follows the same trend, the same mechanism is expected to control the velocity variations.

FE was identified as the main driving mechanism at the daily scale for all the reference case studies involving hard rock sites dislocated by a limited number of rear fractures. These include the nearly 2D rock columns and prisms of LA (Fig. 7), LB, BC and AR, and the 3D geometries of MS (Fig. 5) and MA. The same driving mechanism was considered responsible for $f 1$ and $\mathrm{d} V / V$ fluctuations at the highly fractured COt site (Fig. 6), even if no macroscopic rear fracture was detected on site.

A significant difference in the time of response to the temperature variations between these sites was, however, observed. The response is immediate for MA and MS $(<1 \mathrm{~h}$, Fig. 10) and lower than $2 \mathrm{~h}$ (on average) for LA, while a delay of almost one day was measured on COt (Fig. 10). FE was found to be dominant also at the seasonal scale for the same sites, with the only exception of LA (Fig. 7). At this site, the negative correlation of both $f 1$ and $\mathrm{d} V / V$ with $T$ trends could not be associated with the same driving mechanism. The clear drop in $C C$ values detected at the end of winter months in sitereference configuration is, however, likely due to a drastic change in the rear fracture, preventing the retrieval of $\mathrm{d} V / V$ fluctuations in the following months.

Also at the seasonal scale, sites in which the number, opening and persistence of open fractures are significant if compared to the total volume of the unstable body showed a fast seismic response (e.g., AR and MS), while a delay of more than 1 month was observed at COt (Fig. 10).

Independent measurements from extensometers and crackmeters located across the main open fractures or topographic monitoring of benchmark displacements are available for some of these sites to confirm fracture closing and opening as a result of the rock mass thermal expansion and contraction (Table 3, e.g., Burjánek et al. 2018 for AR; Colombero et al. 2018 for MS).

In general, daily reversible modifications driven by $\mathrm{FE}$ are in the range between $1 \%$ $(\mathrm{COt}$, delay $=23 \mathrm{~h}$ ) and $7 \%(\mathrm{BC})$ for $f 1$ (basing on 7 sites: LA, LB, BC, AR, MS, MA, COt) and between $1.5 \%$ (COt, delay $=18 \mathrm{~h}$ ) and 5\% (MS, no delay) for $\mathrm{d} V / V$ (basing on 3 sites: LA, MS, COt). Seasonal variations controlled by FE are in the range between $4 \%$ (COt, delay $=58 \mathrm{~d}$ ) and $12 \%$ (MS, no delay) for $f 1$ (basing on four sites: AR, MS, MA, COt) and between $2 \%(\mathrm{COb}$, delay $=37 \mathrm{~d}$; PB, delay $=30-50 \mathrm{~d}$ ) and $12 \%$ (MS, no delay) for $\mathrm{d} V / \mathrm{V}$ (basing on four sites: MS, COt, COb, PB). For rock sites, these observations suggest that the higher the number, opening and persistence of fractures with respect to the volume of the unstable compartment, the higher and faster is the seismic response. FE-driven $\mathrm{d} V / V$ reversible variations on landslides $(\mathrm{COb}, \mathrm{PB})$ seem to have lower magnitude and higher delay with respect to rock sites. 


\subsection{Surface Effect (SE)}

Even if FE is commonly addressed as the main driving mechanism of $f 1$ and $\mathrm{d} V / V$ fluctuations in the above-mentioned test sites, its effect may be enhanced by a thermally driven modification in the stress conditions of the rocks. Starr et al. (2015) first introduced this concept of stress-stiffening for MA site. During morning hours, the sandstone of the natural arch showed increasing temperature trends and thermal stresses were found to increase horizontal compression parallel to the arch. This daily temperature-driven modification was confirmed by independent tilt measurements. Beside closure of cracks, compression likely increased grain contact stresses, contributing to bulk stiffening of the rock mass $\left(K_{b}\right.$ increase), with an apparent increase in the bulk elastic moduli (i.e., $E_{b}$ and $G_{b}$ ).

The rock dilation during an increase in air temperature and without phase delay suggests that the heat front remains superficial (Fig. 11b). Therefore, differential dilation between the rock surface and bulk increases internal stresses $\left(\sigma_{i}\right)$ that accordingly increase the bulk stiffness $K_{b}\left(>E_{b}\right.$ and $\left.>G_{b}\right)$ acting as a confinement pressure (Larose and Hall 2009; Tsai 2011) and overcoming an expected minor reduction in the elastic moduli associated with increasing temperature. (See bulk effect in the following subsection.) The result is an increase in $f l$ values and a positive velocity change. The process is reversed with a decrease in temperature.

This mechanism was initially called stress-stiffening by Starr et al. (2015) for MA, and Colombero et al. (2018) recognized it as a possible mechanism, concomitant to FE, for $f 1$ and $\mathrm{d} V / V$ immediate response to air temperature variations at MS cliff at the daily scale (Fig. 5). In this work, we define it as surface effect (SE), to remark that it is primarily linked to heat propagation at the surface of the rock and to distinguish it from the following bulk effect.

SE can be also likely responsible for $f 1$ and $\mathrm{d} V / V$ fluctuations at COt site, where no visible fractures are present to support the identification of $\mathrm{FE}$ as the only driving mechanism.

Given the prerequisite of no heat propagation in the bulk, SE is, however, likely to be more effective at the daily scale, inducing an immediate response in the seismic parameters (no delay or delay close to $0 \mathrm{~h}$ ), while other driving mechanisms are expected to be dominating at the seasonal scale. Due to the likely concomitant FE, it is not possible to separately quantify the range of variations driven by this mechanism.

\subsection{Bulk Effect (BE)}

When heat propagation is able to reach the bulk of the unstable compartment, an inverse temperature-driven modification in the bulk stiffness $K_{b}$ is expected. In concrete, Xia et al. (2011) introduced a linear relationship linking Young's modulus $\left(E_{b}\right)$ and temperature $T$, following:

$$
E_{b}(T)=E_{b}\left(T_{0}\right)\left[1-\theta\left(T-T_{0}\right)\right]
$$

where $T_{0}$ is a reference temperature and $\theta$ is a positive material-dependent coefficient (e.g., $\theta=0.003$ for concrete, from Xia et al. 2011; $\theta=0.012$ and $\theta=0.03$ for dry and saturated limestone, from Tourenq 1970). A decrease in $E_{b}$ is therefore expected with increasing temperatures, causing a decrease in $K_{b}$ and consequently in $f 1$ values (Fig. 11c). The same 
effect is expected on the shear modulus $\left(G_{b}\right)$ of the block, inducing a negative velocity change. The process is then reversed with decreasing temperatures.

Considering a 1-D heat conduction equation (Lowrie 2007), the temperature variation $\Delta T$ at a given depth $z$ and time $t$ is described by:

$$
\Delta T(z, t)=\Delta T_{0} e^{\left(\frac{-z}{d}\right)} \cos \left(\omega t-\frac{z}{d}\right)
$$

with:

$$
d=\sqrt{\frac{2 D}{\omega}}=\sqrt{\frac{2 \lambda}{\omega \rho c_{P}}},
$$

where $\Delta T_{0}$ is the temperature variation at the surface, $\omega$ is the angular frequency of $\Delta T_{0}$, and $D$ is the thermal diffusivity (ratio of thermal conductivity $\lambda$ and heat capacity at constant pressure $c_{P}$ times density $\rho$ ). As a consequence, the temperature variation decreases as a function of depth, with a delay depending on the size, geometry and thermal properties of the unstable compartment.

Bulk effect was identified as the cause of the negative correlation between $T$ and $f 1$ at Les Arches site (Bottelin et al. 2013b) at the seasonal scale ( $\pm 12 \%$; Fig. 7). Cross-correlation between the stations located at the top of the unstable compartment confirmed a similar seasonal response of $\mathrm{d} V / V( \pm 4 \%)$. A delay of 68 days was computed for both $f 1$ and $\mathrm{d} V / V$. Applying Eq. 9, Bottelin et al. (2013b) demonstrated that this delay is high enough to ensure that the whole rock column ( $5 \mathrm{~m}$ thick at the crown) is affected by a pervasive bulk temperature change and thus interpreted $f l$ seasonal variations as a result of this driving mechanism.

At other sites (e.g., MS, Fig. 5), unstable volumes and minimum thicknesses are significantly greater than LA column geometry, making the temperature penetration less efficient on the bulk rock stiffness. By contrast, in case of highly fractured and destructured sites (e.g., LP), BE can be noticed not only at the seasonal scale $( \pm 2 \%$ on $f 1)$, but may be the dominant driving mechanism also at the daily scale ( $\pm 1 \%$ on $f 1$, Fig. 9$)$.

\subsection{Water Effect (WE)}

Water infiltration and accumulation within unstable compartments may play a fundamental role in site stability. If the unstable compartment is susceptible to water retention, an increase in water content causes an increase in mass $(M)$ and density $(\rho)$. A decrease in both contact and bulk shear modulus $\left(G_{b}\right)$ is simultaneously expected due to water seepage. Following Eq. 1 and Eq. 7, a decrease in $f 1$ and a negative $\mathrm{d} V / V$ are then expected (Fig. 12a). Lowering of the water table and drying of the material generate the opposite effect. Seismic parameters are therefore expected to show a negative correlation with the precipitation $(P)$ amount.

Perturbations in the $T$-driven variations were observed at three sites on $f l$ (AR, COt, $\mathrm{MH}$ ) and $\mathrm{d} V / V(\mathrm{COt}, \mathrm{COb}, \mathrm{PB})$. These modifications are negatively correlated with $P$. A clear decrease in $f 1$, not correlated with $T$, was detected at AR by Burjánek et al. (2018) during spring months. This drop (from approximately $3.5 \mathrm{~Hz}$ to $3.3 \mathrm{~Hz}$ in 10 days, around $-4 \%$ ) was possibly related to the rise of the water table consequent to snow melt in the area surrounding the unstable site and to higher precipitation rates recorded during 
the period ( $>20 \mathrm{~mm} / \mathrm{d}$ for several days in the month preceding $f 1$ drop). Similarly, the most intense daily precipitation peak recorded at COt $(30 \mathrm{~mm} / \mathrm{d}$, blue window in Fig. 6a) caused a significant drop ( $-4 \%$ on $f 3$ and $-2.5 \%$ on $\mathrm{d} V / V$, from Valentin 2018 ) overcoming the $T$-related seismic variations $( \pm 1 \%$ at the daily scale). A rapid decay in $f 3$ was detected at MH by Weber et al. (2018) during the melting/thawing season and in summer months, which can be related to water effect.

No modifications in the $T$-related $f 1$ or $\mathrm{d} V / V$ trends were observed at the other rock sites (LA, MS, MA) and on the destructured slope of LP. Rock sites with open rear fractures may drain the amount of infiltrated water more effectively and faster, without water retention within the unstable volumes (e.g., MS, Fig. 5; LA, Fig. 7). As a consequence, their $T$-driven seismic fluctuations are not affected by WE.

For both landslides in destructured materials, likely more prone to water accumulation, drops in $\mathrm{d} V / V$ correlated with $P$ were observed in discrete time windows $(-1.5 \%$ at $\mathrm{COb}$; up to $-4 \%$ at $\mathrm{PB}$ ). In particular, at $\mathrm{PB}$, Mainsant et al. (2012) recognized a $\mathrm{d} V / V$ drop of $-2 \%$ in July 2010 developing over 20 days after an intense rainfall peak $(\sim 35 \mathrm{~mm} / \mathrm{d})$ analyzing the period between April and September 2010. Larose et al. (2015) expanded the analysis up to July 2014 , finding a significant $\mathrm{d} V / V$ drop of approximately $-4 \%$ within one month, developing during a week with continuous heavy $P(160 \mathrm{~mm} /$ week $)$ in autumn 2011. Bièvre et al. (2018) considered the whole monitored period (2010-2016) and quantified the delay of $\mathrm{d} V / V$ response to $P$ in 2-7 days.

\subsection{Ice Effect (IE)}

If intense precipitations are accompanied or followed by a decrease in air temperature below $0{ }^{\circ} \mathrm{C}$, ice formation can occur in fractures and microcracks (Fig. 12b). The presence of ice significantly increases the fracture contact stiffness $\left(K_{c}\right)$, with a consequent increase in $f l$ and positive $\mathrm{d} V / V$. The process is reversed at the end of the freezing period.

The increase in $f l$ due to ice formation in the rear fracture was observed to be high (from 5 to $24 \mathrm{~Hz}$ ) and persistent over several months (mid-November-late April) at LA site $(+300 \%$, Fig. 7 b). During these months, only minor decreases of $f 1$ were detected during periods in which $T$ rose above $0{ }^{\circ} \mathrm{C}$ for several days. High CC values detected over the same period in site-reference cross-correlation (Fig. $7 \mathrm{~g}$ ) support the hypothesis of ice presence, strengthening the contact stiffness between the column and the stable cliff and improving the correlation between the sensor recordings. No significant velocity changes are detected while ice is present in the rear fracture, while local velocity and CC drops are depicted in the days in which $T$ rises and persists above $0{ }^{\circ} \mathrm{C}$, in analogy with $f 1$ trend. After ice melting in late April 2011, cross-correlation is almost lost between stable and unstable sensor locations (Fig. $7 \mathrm{~g}$ ) and a trend in $\mathrm{d} V / V$ (Fig. 7f) cannot be retrieved.

On shorter time windows, ice effect is also detected in COt data (Fig. 6, green window). Intense rainfalls followed by a temperature drop below $0{ }^{\circ} \mathrm{C}$ cause a clear peak in $f 3$ $(+8 \%)$ and $\mathrm{d} V / V(+2.5 \%)$, both overcoming the daily $T$-driven variations ranges $( \pm 2.5 \%$ and $\pm 1.5 \%$, respectively). The $P$-driven deviation from the trend is, however, recovered after a few days.

In general, IE depends both on the ability of the unstable body and fractures to accumulate water and on the climatic conditions in which the site is located. As an example, at $\mathrm{MH}$ (i.e., field site located on the North-East ridge of Matterhorn Peak, in the Swiss Alps, at an elevation of $3500 \mathrm{~m}$ a.s.l.), an increase in $f 3$ from $15 \mathrm{~Hz}$ up to $50 \mathrm{~Hz}$ (around +230\%) due to ice formation is reported in Weber et al. (2018). This resonance frequency is observed 
to vary seasonally with four distinct phases: persistent decrease during summer, rapid increase during freezing, trough-shaped pattern in winter and a sharp peak with a rapid decay during the melting/thawing season. IE is dominant at the site and even masks minor fluctuations of the resonance frequencies induced by other driving mechanisms.

\subsection{Clay Effect (CE)}

Daily and seasonal variations of all the reference sites can be referred to one or more of the above-reported driving mechanisms, with the exception of HA clayey block behavior (Fig. 8). Only for this site, $f 1-T$ negative correlation and $f 1-P$ positive correlation simultaneously occurred.

The increase in $f 1$ when $T$ decreases $( \pm 5 \%$ at the daily scale; $\pm 12 \%$ in the monitored four months) could be explained by the contractive behavior of clay with increasing temperature, as it has been observed by several authors for normally consolidated clays (Cekerevac and Laloui 2004; Favero et al. 2016). In Harmalière landslide, Bièvre (2010) suggested that the clay material is normally consolidated to under-consolidated (OCR ratio $\leq 1)$. Clay contraction (expansion) when $T$ increases (decreases) induces an opening (closing) of the superficial fracture and a decrease (increase) in $f 1$ (Fig. 12c). This thermal effect was observed on $f 1$, while $\mathrm{d} V / V$ showed only a small variation $(<2 \%)$ during the first 2.5 months, with no obvious correlation with temperature. On the other hand, precipitations and consequent water infiltration induced local increases in $f 1$ and $\mathrm{d} V / V$ (positive correlation, yellow windows in Fig. 8), by contributing to moisten the clay material and attenuate its contraction.

In addition, unlike all other sites, a gradual increase (from 4 to $12 \mathrm{~h}$ ) in the response time of $f l$ to $T$ was detected from August to mid-October 2016 (Fig. 8c), prior to severe disturbances in the last 40 days before the block collapse. The causative mechanisms generating this peculiar seismic response are unclear and may be related to the ongoing modifications in the mechanical properties of clays in the last months before failure. In particular, a recurrent succession of swelling and shrinkage of the block may have caused increasing delay in the thermal reaction of the clay. This hypothesis cannot be supported by other field observations, but is consistent with experimental studies (e.g., Di Donna and Laloui 2015) demonstrating an accommodative behavior of clay materials with an increasing number of heating-cooling cycles.

\subsection{Synthesis}

Tables 7 and 8 summarize the observations made at all sites, as well as the proposed driving mechanisms for $f l$ and $\mathrm{d} V / V$ variations, respectively. In all the continuous seismic noise monitoring studies, reversible effects of the meteorological factors ( $T$ and $P$ ) were observed on the seismic parameters $(f l$ and $\mathrm{d} V / V)$ at the daily and seasonal scales, with different trends and significant differences in variation ( 1 to $12 \%$ while $T>0{ }^{\circ} \mathrm{C} ; 0$ to $300 \%$ while $T<0{ }^{\circ} \mathrm{C} ; 0$ to $10 \%$ in response to $P$ ). Temperature was identified as the main controlling factor of both $f 1$ and $\mathrm{d} V / V$ reversible variations. While air temperature is higher than $0{ }^{\circ} \mathrm{C}$, $T$-driven daily variations are in the range $1-7 \%$ for $f 1$ and $1.5-5 \%$ for $\mathrm{d} V / V$, with delays of $0-23 \mathrm{~h}$ and $0-18 \mathrm{~h}$, respectively. $T$-driven seasonal variations are in the range $2-12 \%$ for both $f 1$ and $\mathrm{d} V / V$ with delays of $0-68$ days for both parameters. 
Table 7 Daily and seasonal variations of $f 1$ recorded at the reference case studies

\begin{tabular}{|c|c|c|c|c|c|c|}
\hline \multirow[b]{2}{*}{ Site } & \multicolumn{2}{|c|}{ f1 daily variations } & \multicolumn{4}{|c|}{ f1 seasonal variations } \\
\hline & Range & \begin{tabular}{|c|} 
Driving \\
mechanism
\end{tabular} & $\begin{array}{l}\text { Range } \\
T>0^{\circ} \mathrm{C}\end{array}$ & $\begin{array}{l}\text { Range } \\
\boldsymbol{T}<0^{\circ} \mathrm{C}\end{array}$ & $\begin{array}{c}\text { Range } \\
\boldsymbol{P}\end{array}$ & $\begin{array}{c}\text { Driving } \\
\text { mechanism }\end{array}$ \\
\hline LA & $\begin{array}{c} \pm 5 \% \\
\text { delay }=1.6 \mathrm{~h} \\
(0-5 \mathrm{~h})\end{array}$ & FE & $\begin{array}{c} \pm 12 \% \\
\text { delay }=68 d\end{array}$ & up to $+300 \%$ & $\begin{array}{l}\text { No change } \\
\text { in } f 1 \text { trend }\end{array}$ & $\mathrm{BE}+\mathrm{IE}$ \\
\hline LB & $\begin{array}{c} \pm 5 \% \\
\text { no delay }\end{array}$ & FE & \multicolumn{4}{|c|}{ Insufficient data } \\
\hline $\mathrm{BC}$ & $\pm 7 \%$ & FE & \multicolumn{4}{|c|}{ Insufficient data } \\
\hline $\mathrm{AR}$ & Not quantified & FE & $\begin{array}{c} \pm 6 \% \\
\text { delay }=0.1 \mathrm{~d}\end{array}$ & $\begin{array}{c}\text { Not quantified } \\
\text { delay }=4 \mathrm{~d}\end{array}$ & Around $-4 \%$ & $\begin{array}{c}\text { FE- IE -WE } \\
\text { (spring) }\end{array}$ \\
\hline $\mathrm{MH}$ & \multicolumn{2}{|c|}{ Not quantified } & Not quantified & around $+230 \%$ & Not quantified & IE \\
\hline MS & $\begin{array}{c} \pm 5 \% \\
\text { delay<1 } \mathrm{h}\end{array}$ & \begin{tabular}{|c|} 
FE \\
(and/or SE)
\end{tabular} & $\begin{array}{c} \pm 12 \% \\
\text { delay<1 d }\end{array}$ & $\begin{array}{l}\text { No change } \\
\text { in f1 trend }\end{array}$ & $\begin{array}{l}\text { No change } \\
\text { in } 11 \text { trend }\end{array}$ & FE \\
\hline MA & $\begin{array}{c} \pm 3 \% \\
\text { no delay }\end{array}$ & $\begin{array}{c}\text { FE } \\
\text { (and/or SE) }\end{array}$ & Not quantified & Not quantified & $\begin{array}{l}\text { No change } \\
\text { in } 11 \text { trend }\end{array}$ & FE-IE \\
\hline $\mathrm{cOt}$ & $\begin{array}{c} \pm 1 \%(f 1) \\
\pm 2.5 \%(f 3) \\
\text { delay=23 h (f3) } \\
\end{array}$ & FE (SE?) & $\begin{array}{c} \pm 4 \%(f 1) \\
\pm 6 \%(f 3) \\
\text { delay=58 d (f3) }\end{array}$ & up to $+8 \%(f 3)$ & $-4 \%(f 3)$ & FE - IE -WE \\
\hline $\mathrm{COb}$ & \multicolumn{6}{|c|}{ No data } \\
\hline PB & \multicolumn{6}{|c|}{ No data } \\
\hline $\mathrm{HA}$ & $\begin{array}{c} \pm 5 \% \\
\text { delay= } 4-12 \mathrm{~h} \\
\text { (variable over time) }\end{array}$ & CE & $\begin{array}{l} \pm 12 \% \text { ** } \\
\left({ }^{* *} 4 \text { months }\right)\end{array}$ & $\begin{array}{c}\text { Insufficient } \\
\text { data }\end{array}$ & Up to $+12 \%$ & $\mathrm{CE}+\mathrm{CE}$ \\
\hline LP & $\pm 1 \%$ & $B E$ & $\pm 2 \%$ & No data & $\begin{array}{l}\text { No change } \\
\text { in } 11 \text { trend }\end{array}$ & BE \\
\hline
\end{tabular}

Percentage of variation and delay are reported for sites with available information. At the seasonal scale, the seismic response is differentiated between periods with air temperature $T$ higher or lower than $0{ }^{\circ} \mathrm{C}$; the effect of precipitation $P$ is also reported. Green (red) cells: positive (negative) correlation between the considered meteorological factor and $f 1$. Gray cells: no change with respect to the $T$-driven trend $\left(T>0{ }^{\circ} \mathrm{C}\right)$. No data: no $f 1$ data for evaluating the variations. Insufficient data: $f 1$ data are computed on a time window which is too short to evaluate the seismic parameter variations. Not quantified: $f 1$ data are computed in the original work, but the temporal variations are not quantified (positive or negative correlation with the meteorological parameter is however indicated for some sites by the original authors). Driving mechanisms: FE (fracture effect), SE (surface effect), BE (bulk effect), WE (water effect), IE (ice effect) and CE (clay effect). For seasonal variations, the driving mechanism during periods with positive (negative) temperature is indicated in normal (bold) font, and in italics for precipitation. In the last column, the symbols + and - indicate a conjugated or opposite effect of the mentioned driving mechanisms with respect to the trend of $T>0{ }^{\circ} \mathrm{C}$

Three driving mechanisms, among the six identified in the literature, are purely thermal (FE, SE, BE), while water plays or can play a role in the other three (WE, IE, CE). The first two mechanisms (FE and SE) generate a positive correlation between seismic parameters and $T$ fluctuations, in contrast to the third one (BE) which causes an inverse trend.

On a daily scale, FE appears to be the most common mechanism to explain variations of both seismic parameters at rock sites (LA to COt, 1-7\%, Tables 7 and 8). Higher magnitudes of the variations, associated with short delays, are observed at rock sites with one or more persistent open fractures (LA, LB, BC, MS: $f 1$ and $\mathrm{d} V / V$ range of variation 2-7\%, delay $=0-1.6 \mathrm{~h}$ ). In contrast, lower variations and longer delays are depicted on sites with no apparent fractures (COt: 1-1.5\%, delay=18-23 h). Surface effect (SE), which is difficult to distinguish from FE, is explicitly evoked only at two rock sites (MA and MS) but may have contributed to the seismic parameters variations detected at COt cliff, where 
Table 8 Daily and seasonal variations of $\mathrm{d} V / V$ recorded at the reference case studies

\begin{tabular}{|c|c|c|c|c|c|c|}
\hline \multirow{2}{*}{ Site } & \multicolumn{2}{|c|}{$\mathrm{d} V / V$ daily variations } & \multicolumn{4}{|c|}{$\mathrm{d} V N$ seasonal variations } \\
\hline & Range & $\begin{array}{c}\text { Driving } \\
\text { mechanism }\end{array}$ & $\begin{array}{l}\text { Range } \\
T>0^{\circ} \mathrm{C}\end{array}$ & $\begin{array}{l}\text { Range } \\
T<0^{\circ} \mathrm{C}\end{array}$ & $\begin{array}{l}\text { Range } \\
\text { water }\end{array}$ & $\begin{array}{c}\text { Driving } \\
\text { mechanism }\end{array}$ \\
\hline LA & $\begin{array}{c} \pm 2 \% \\
\text { delay }=1.6 \mathrm{~h} \\
(0-4 \mathrm{~h})\end{array}$ & FE & $\begin{array}{c} \pm 4 \% \\
\text { delay }=68 \mathrm{~d}\end{array}$ & $\begin{array}{c}\text { No change } \\
\text { in } \mathrm{d} V / V \text { trend } \\
\text { (?) }\end{array}$ & $\begin{array}{l}\text { No change } \\
\text { in f1 trend }\end{array}$ & $\mathrm{BE}$ \\
\hline LB & \multicolumn{6}{|c|}{ No data } \\
\hline $\mathrm{BC}$ & \multicolumn{6}{|c|}{ No data } \\
\hline AR & \multicolumn{6}{|c|}{ No data } \\
\hline $\mathrm{MH}$ & \multicolumn{6}{|c|}{ No data } \\
\hline MS & $\begin{array}{c} \pm 5 \% \\
\text { delay<1 } \mathrm{h}\end{array}$ & $\begin{array}{c}\text { FE } \\
\text { (and/or SE) }\end{array}$ & $\begin{array}{c} \pm 12 \% \\
\text { delay<1 d }\end{array}$ & $\begin{array}{c}\text { No change } \\
\text { in } \mathrm{d} V / \mathrm{V} \text { trend }\end{array}$ & $\begin{array}{c}\text { No change } \\
\text { in } \mathrm{dV} / \mathrm{V} \text { trend }\end{array}$ & FE \\
\hline MA & \multicolumn{6}{|c|}{ No data } \\
\hline cOt & $\begin{array}{c} \pm 1.5 \% \\
\text { delay=18 h }\end{array}$ & FE (SE?) & $\begin{array}{c} \pm 4 \% \\
\text { delay }=63 \mathrm{~d}\end{array}$ & Up to $+2.5 \%$ & $-2.5 \%$ & $\mathrm{FE}-\mathrm{IE}-W E$ \\
\hline $\mathrm{COb}$ & \multicolumn{2}{|c|}{ Not quantified } & $\begin{array}{c} \pm 2 \% \\
\text { delay }=37 \mathrm{~d}\end{array}$ & $\begin{array}{c}\text { No change } \\
\text { in } \mathrm{dV} V \text { trend }\end{array}$ & $-1.5 \%$ & $F E-W E$ \\
\hline PB & \multicolumn{2}{|c|}{ Not quantified } & $\begin{array}{c} \pm 2 \% \\
\text { delay }=30-50 \\
d\end{array}$ & $\begin{array}{c}\text { No change } \\
\text { in } \mathrm{d} V / V \text { trend }\end{array}$ & $\begin{array}{c}\text { Up to }-4 \% \\
\text { delay }=2-7 \mathrm{~d}\end{array}$ & $\mathrm{FE}-W E$ \\
\hline $\mathrm{HA}$ & \multicolumn{2}{|c|}{ Not quantified } & $\begin{array}{c} \pm 2 \%{ }^{*} \\
\text { (*4 months) } \\
\end{array}$ & $\begin{array}{c}\text { Insufficient } \\
\text { data }\end{array}$ & Up to $+10 \%$ & $C E$ \\
\hline LP & \multicolumn{6}{|c|}{ No data } \\
\hline
\end{tabular}

Percentage of variation and delay are reported for sites with available information. At the seasonal scale, the seismic response is differentiated between periods with air temperature higher or lower than $0{ }^{\circ} \mathrm{C}$; the effect of precipitation $P$ is also reported. Green (red) cells: positive (negative) correlation between the considered meteorological factor and $\mathrm{d} V / V$. Blue cells: no correlation with $T$. Gray cells: no change with respect to the $T$-driven trend $\left(T>0{ }^{\circ} \mathrm{C}\right)$. No data: no $\mathrm{d} V / V$ data for evaluating the variations. Insufficient data: $\mathrm{d} V / V$ data are computed on a time window which is too short to evaluate the seismic parameter variations. Not quantified: $\mathrm{d} V / V$ data are computed in the original work, but the temporal variations are not quantified (positive or negative correlation with the meteorological parameter is however indicated for some sites by the original authors). Driving mechanisms: FE (fracture effect), SE (surface effect), BE (bulk effect), WE (water effect), IE (ice effect) and CE (clay effect). For seasonal variations, the driving mechanism during periods with positive (negative) temperature is indicated in normal (bold) font, and in italics for precipitation. In the last column, the symbols + and - indicate a conjugated or opposite effect of the mentioned driving mechanisms with respect to the trend of $T>0{ }^{\circ} \mathrm{C}$

apparently no visible fractures are present, even if the seismic response to $T$ is significantly delayed. For the two instabilities with soil conditions or very destructured material (HA and LP, no rear fractures), clay effect and bulk effect are, respectively, proposed to explain the daily negative correlation between resonance frequency and $T$, with a maximum $f l$ variation of $5 \%$ (HA, Table 7).

On a seasonal scale, most rock sites and two soil sites (PB and $\mathrm{COb}$ ) exhibit a positive correlation between seismic parameters and $T$. FE (or crack effect in soils) is again proposed as the main driving mechanism, generating variations in the order of 2 to $12 \%$. Only LA site shows negative correlation with $T$ associated with considerable delay in the seismic response (68 d), interpreted as the result of $T$ propagation in the bulk of the very thin column (BE). In strongly destructured materials (LP) and clays (HA), there is a negative 
correlation between $f 1$ and $T$, with two different mechanisms (BE and CE) generating weak $( \pm 2 \%)$ and strong $f 1( \pm 12 \%)$ variations, respectively.

The highest recorded reversible variations in seismic parameters (LA: $f 1$ up to $300 \%$; $\mathrm{MH}: f 3$ around $+230 \%$, negative correlation with $T$ ) are associated with ice formation in fractures, starting during periods with air temperature lower than $0{ }^{\circ} \mathrm{C}$, concomitant or following intense precipitations, and potentially lasting throughout the winter. IE was mainly detected on rock sites (LA, AR, MH, MA and COt) and depends on both the ability of unstable body/fractures to accumulate water and the climatic conditions in which the site is located.

Finally, it has been shown that precipitation causes a decrease in $f 1$ and $d V / V$ on rock and soil sites (AR, COt, $\mathrm{COb}, \mathrm{PB}, f 1$ and $\mathrm{d} V / V$ range of variation $1.5-4 \%$ ), which has been interpreted as resulting from water infiltration (WE). An exception is HA clayey site where $f 1$ and $d V / V$ increase up to $10-12 \%$ after precipitation, in line with the particular shrink-swell behavior of clay.

\section{Discussion and Conclusions}

Resonance frequency $(f l)$ and velocity changes $(\mathrm{d} V / V)$ are easy-to-monitor seismic noise parameters that showed significant variations before the occurrence of landslides both in rock and in soil conditions (Lévy et al. 2010; Mainsant et al. 2012; Bertello et al. 2018; Fiolleau et al. 2020). It was found that these parameters can irreversibly drop over a period of time ranging from a few days to a few weeks prior to failure, with an irrecoverable decrease ranging from 7\% (Mainsant et al. 2012) to 50\% (Bertello et al., 2018). Twelve case histories of long-term continuous ambient seismic monitoring of unstable rock sites and earthslides were reviewed with the aim of analyzing the reversible seismic parameter changes driven by meteorological factors (air temperature $T$ and precipitation $P$ ) at the seasonal and daily scales. In all sites, seismic parameters showed significant reversible variations at both timescales under weather stresses, which have to be understood in order to use these parameters as precursors of failure. Six $T$-, $P$ - and $T-P$-driven mechanisms have been proposed to explain these reversible variations that can show highly variable effects in terms of amplitude and delay. The synthesis of the collected data shows that the most referenced driving mechanism at rock sites is the $T$-driven fracture effect (possibly coupled with surface effect) capable of generating seismic parameter variations of up to $\pm 12 \%$. Clay effect can also cause variations of a similar magnitude, at least on a seasonal scale. When it occurs, ice effect can significantly increase $f 1$ values (up to $300 \%$ ). Bulk effect and water effect seem to generate less significant parameter variations $(<5 \%)$.

The recognized driving mechanisms may act separately or simultaneously, reinforcing each other or generating opposite effects on the seismic parameters. The magnitude of the consequent seismic fluctuations and the related delay in the response to external modifications are strictly depending on the site geometry, fracturing and general stability conditions. Considering the few rock sites with both $f 1$ and $\mathrm{d} V / V$ data, a similar thermal response of the two seismic parameters is observed only for two sites (MS and $\mathrm{COt}$ ). For these two cases, cross-correlations computed in the same frequency band of the resonance frequencies show the highest $C C$ values and $\mathrm{d} V / V$ variations mirroring the frequency trend. At the other two sites (HA and LA), fl can be tracked and monitored over time, while $\mathrm{d} V / V$ fluctuations are complex and not coherent with the $T$-driven evolution of $f l$. For LA site, $\mathrm{d} V / V$ computed between the two sensors located on the 
unstable column is $T$-dependent during the non-freezing period (i.e., no ice filling the rear fracture to strengthen the constraint of the unstable volume). These results suggest that, for rock sites where the reference station is located very close to the unstable compartment (and/or the opening and persistence of the back fracture does not completely decouple it), noise recordings of the stable site are influenced by the resonance of the unstable column and show low-amplitude spectral peaks (e.g., for MS, Colombero et al. 2018). Under these conditions, $d V / V$ recovered in the frequency band of $f 1$ follows the same temporal variations and is thus sensitive to the same driving mechanisms. On the other hand, if no spectral peaks are visible at the reference station (e.g., for LA, Bottelin et al. 2013a) due to either a significant distance or decoupling from the potentially unstable compartment, cross-correlation in the frequency band of $f 1$ gives low $C C$ values and it is impossible to recover consistent $\mathrm{d} V / V$ values. If the coupling of stable and unstable sectors is strengthened (e.g., by ice filling the rear fracture during winter months at LA), cross-correlation increases significantly.

With the exception of ice formation that generates a marked increase in $f 1$ and $\mathrm{d} V / V$, all the other mechanisms can induce reversible decreases in the monitored parameters similar to the effects of irreversible damage prior to failure. In addition, the range of variations due to reversible effects ( 1 to $12 \%$ ) partially overlaps the range of irreversible changes observed prior to failure (7 to 50\%). It is therefore essential to assess and understand the $T$ - and $P$-driven reversible fluctuations of the seismic parameters at a given site. Prediction methods based on the calibration of the relationship between seismic and meteorological parameters can be used to correct $f l$ and $\mathrm{d} V / V$ time series for reversible meteorological effects (Bottelin et al. 2017; Colombero et al. 2018). This treatment, which allows only irreversible mechanical effects to be retained, is essential to avoid misinterpretations or false alarms in early warning systems. Finally, this synthesis also raises the question of possible changes in the sensitivity of seismic parameters to meteorological factors during the evolution toward failure. Indeed, the reversible variations result from hydro-thermomechanical coupling phenomena and provide information on the stability conditions and their evolution. Changes in the sensitivity to temperature of certain resonance frequencies were observed for PB rock column during reinforcement works (Bottelin et al. 2017) and were interpreted as a partial closing or filling of the rear fracture. Conversely, as a fracture gradually opens, it is likely that certain resonance modes become more sensitive to temperature variations. However, existing data are still too sparse to draw conclusions on this issue.

This study clearly highlighted the interest of using ambient seismic noise parameters for monitoring purposes, but it also pointed out that the quantitative understanding of the driving mechanisms and their impacts remains incomplete. Future perspectives should be devoted to the design of controlled laboratory tests to quantify the separate and combined seismic effects on several rock and soil types, coupled with multi-physics numerical modeling studies.

\section{Appendix}

\section{Daily and Seasonal Delay Computation}

In this Appendix, we describe the procedure adopted for the computation of the delay between daily and seasonal variations of the seismic and meteorological parameters in 

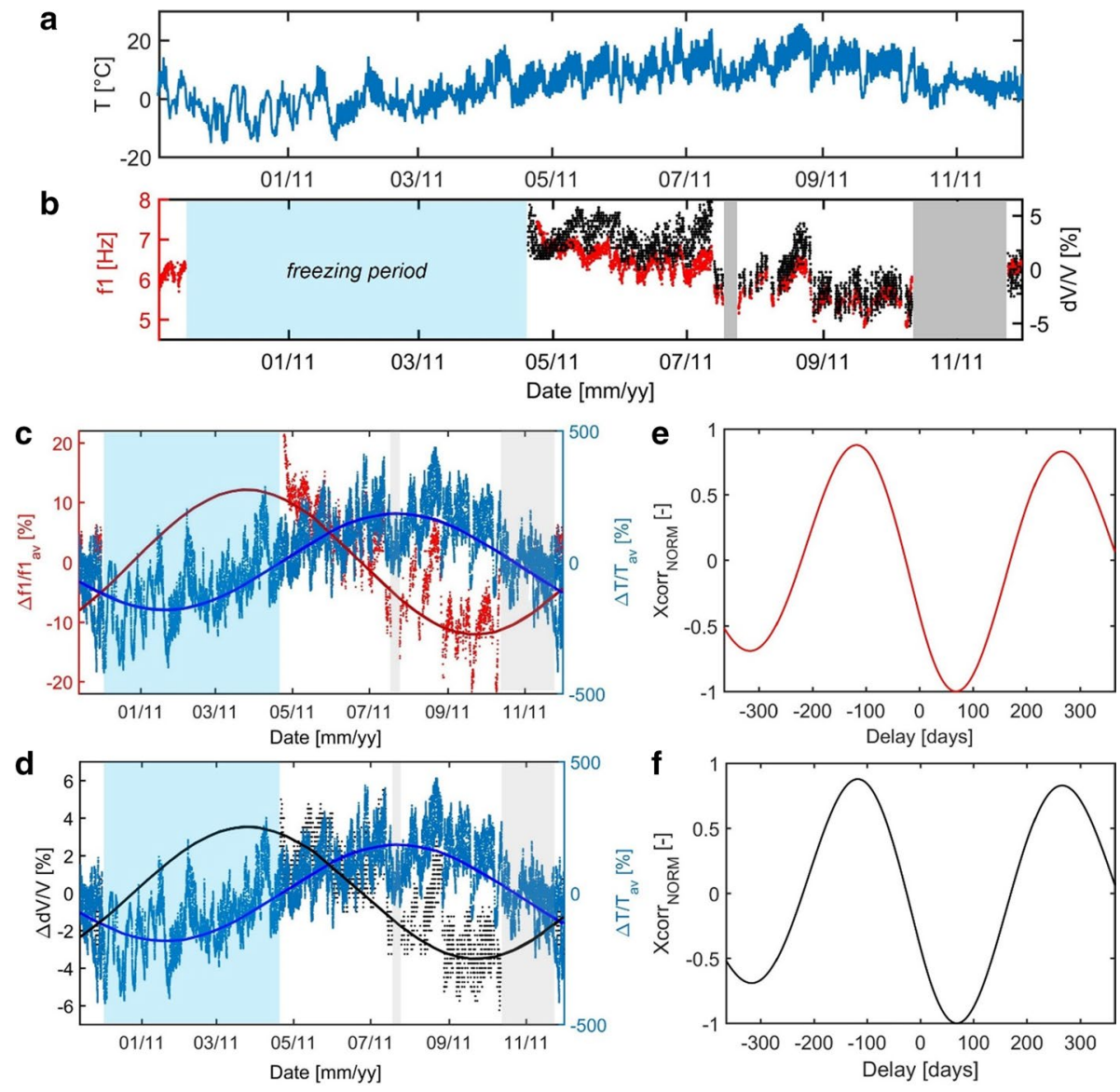

Fig. 13 Correlation between seismic and meteorological parameters at the seasonal scale for LA site. a Air temperature. b $f 1$ (in red) and $\mathrm{d} V / V$ (in black) during non-freezing period (blue window). Periods with no data are marked in gray. c Least square sine-fitted $f 1$ and $T$ data. d Least square sine-fitted $\mathrm{d} V / V$ and $T$ data. e Zoom on the central part of the normalized cross-correlogram between $f 1$ and $T$. f Zoom on the central part of the normalized cross-correlogram between $\mathrm{d} V / V$ and $T$

most of the reference works of Table 1 . In particular, $f 1$ and $\mathrm{d} V / V$ daily and seasonal variations recorded at LA site (while $T<0{ }^{\circ} \mathrm{C}$ ) are compared with the temperature trend and the related delays in the response are computed.

\section{Seasonal Variations}

To analyze seasonal variations (Fig. 13), sine curves were least square fitted to $T, f l$ and $\mathrm{d} V / V$ data, after demeaning and normalizing each data set to the average value (Fig. $13 \mathrm{c}$, and d). Cross-correlation of $f 1$ and $\mathrm{d} V / V$ sine curves with $T$ gave negative correlation coefficients, with a delay of 68 days for both seismic parameters. (See location of the minima in the cross-correlograms of Fig. 13e and f.) 

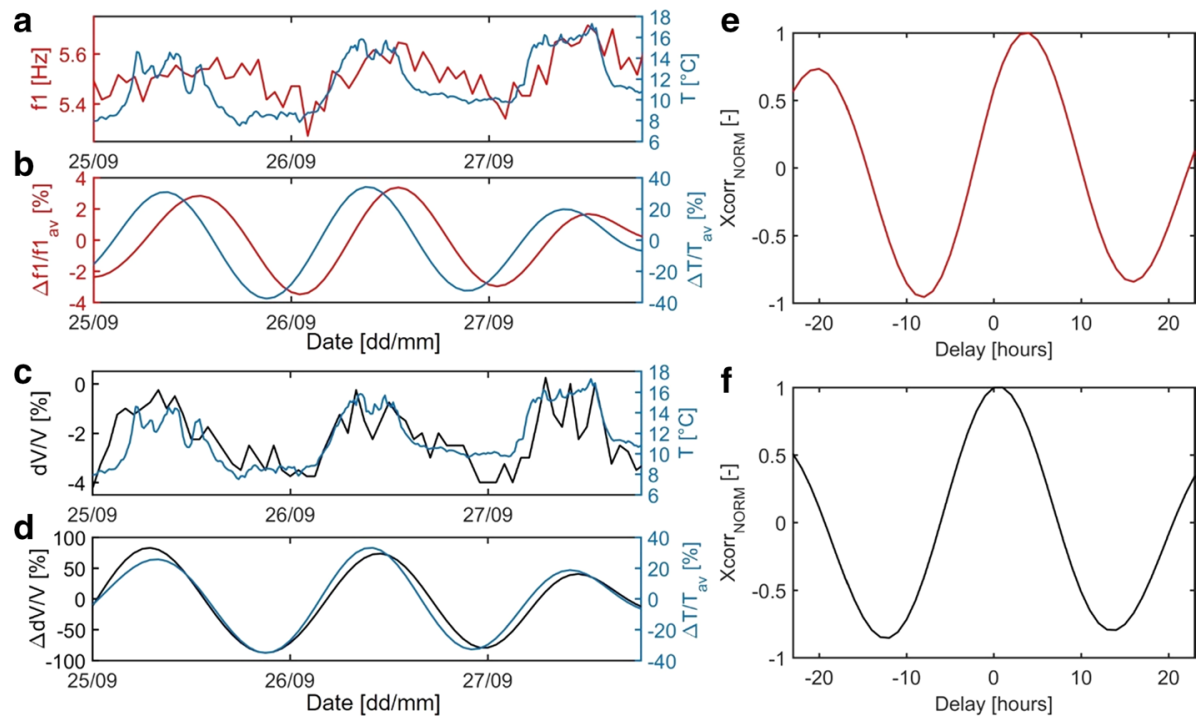

Fig. 14 Correlation between seismic and meteorological parameters at the daily scale for LA site, on an exemplificative 3-day time window (September 25-27, 2011). a $f 1$ and $T$ raw data. b Demeaned daily-filtered $f 1$ and $T$ data. $\mathbf{d} \mathrm{d} V / V$ and $T$ raw data. e Demeaned daily-filtered $f 1$ and $T$ data. e Zoom on the central part of the normalized cross-correlogram between $f 1$ and $T$. (f) Zoom on the central part of the normalized cross-correlogram between $\mathrm{d} V / V$ and $T$

\section{Daily Variations}

To analyze daily variations, short windows with continuous $f 1$ and $\mathrm{d} V / V$ data (e.g., Figure $14 \mathrm{a}$ and $\mathrm{c}$ ) were cross-correlated with $T$. Demeaned and normalized data sets were

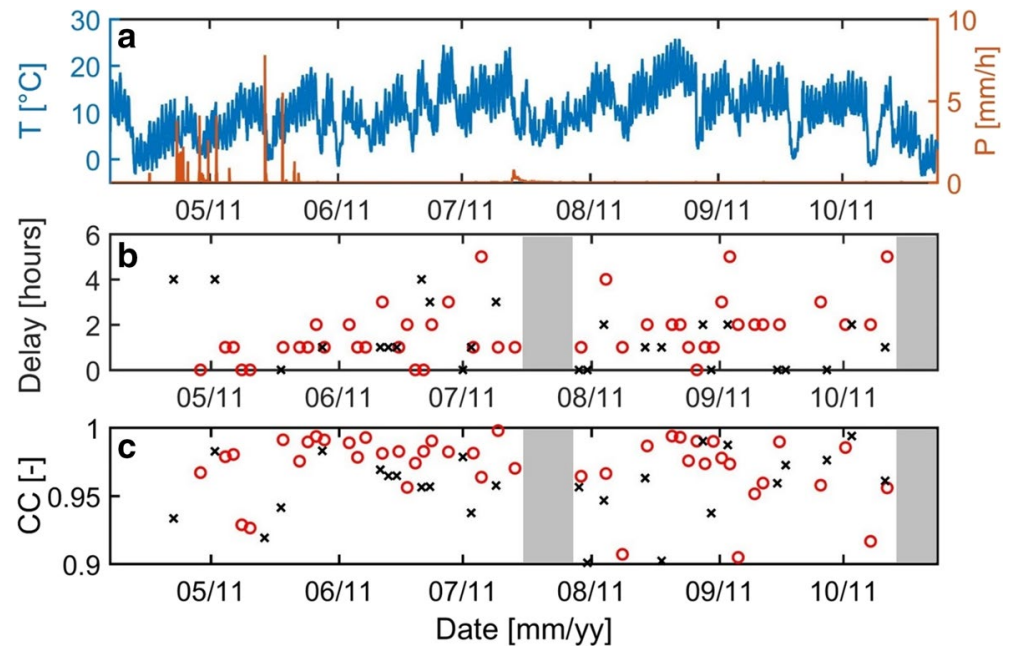

Fig. 15 a Air temperature and hourly rainfall amounts. b Delay obtained from $f 1$ (red circles) and $\mathrm{d} V / V$ (black crosses). c Related correlation coefficients 
daily-filtered (Fig. 14b and d) to enhance the periodicity of interest. Cross-correlation of both $f l$ and $\mathrm{d} V / V$ with $T$ gave positive correlation coefficients at the daily scale (Fig. 14e and $f$ ), with a few hours of delay.

Slight differences in the delays were observed between the two seismic parameters ( $4 \mathrm{~h}$ for $f 1$, Fig. 14e; $2 \mathrm{~h}$ for $\mathrm{d} V / V$, Fig. 14f). These minor differences in the estimated delays may depend on the data windows used for cross-correlation (i.e., length and period of the year) and on the related data quality. As a consequence, to obtain a reliable estimation of the average delay over the whole analyzed period, a moving window of 5 days with $50 \%$ overlap was shifted along the data set. On each window, demeaned, normalized and daily-filtered $f 1, \mathrm{~d} V / V$ and $T$ data were cross-correlated. To ensure a robust estimate of the delay, time windows with $C C<0.9$ were rejected. The delays estimated on the remaining time windows are shown in Fig. 15b (related $C C$ in Fig. 15c); $f 1$ delay varies over time from 0 to $5 \mathrm{~h} ; \mathrm{d} V / V$ delays are observed in a similar range $(0-4 \mathrm{~h})$. The average delay of both $f 1$ and $\mathrm{d} V / V$ is approximately $2 \mathrm{~h}$.

Funding Open Access funding provided by Politecnico di Torino.

Open Access This article is licensed under a Creative Commons Attribution 4.0 International License, which permits use, sharing, adaptation, distribution and reproduction in any medium or format, as long as you give appropriate credit to the original author(s) and the source, provide a link to the Creative Commons licence, and indicate if changes were made. The images or other third party material in this article are included in the article's Creative Commons licence, unless indicated otherwise in a credit line to the material. If material is not included in the article's Creative Commons licence and your intended use is not permitted by statutory regulation or exceeds the permitted use, you will need to obtain permission directly from the copyright holder. To view a copy of this licence, visit http://creativecommons.org/licenses/by/4.0/.

\section{References}

Bendat JS, Piersol AG (1971) Random data: analysis and measurement procedures. Wiley, New York

Bertello L, Berti M, Castellaro S, Squarzoni G (2018) Dynamics of an active earthflow inferred from surface wave monitoring. J Geophys Res Earth Surf 123:1811-1834. https://doi.org/10.1029/2017JF004233

Bièvre G (2010) Caractérisation de versants argileux instables dans des conditions hydrogéologiques hétérogènes. Approche géophysique. PhD thesis in Geophysics [physics.geo-ph], Université Joseph-Fourier, Grenoble I

Bièvre G, Franz M, Larose E, Carrière S, Jongmans D, Jaboyedoff M (2018) Influence of environmental parameters on the seismic velocity changes in a clayey mudflow (Pont-Bourquin Landslide, Switzerland). Eng Geol 245:248-257. https://doi.org/10.1016/j.enggeo.2018.08.013

Bottelin P, Jongmans D, Baillet L, Lebourg T, Hantz D, Lévy C, Le Roux O, Cadet H, Lorier L, Rouiller JD, Turpin J, Darras L (2013a) Spectral analysis of prone-to-fall rock compartments using ambient vibrations. J Environ Eng Geophys 18:205-217. https://doi.org/10.2113/jeeg18.4.205

Bottelin P, Lévy C, Baillet L, Jongmans D, Guéguen P (2013b) Modal and thermal analysis of Les Arches unstable rock column (Vercors massif, French Alps). Geophys J Int 194:849-858. https://doi.org/10.1093/ gji/ggt046

Bottelin P (2014) Caractérisation des phases pré-et post-rupture d'éboulements rocheux de taille intermédiaire: Apport des enregistrements sismiques. $\mathrm{PhD}$ thesis in Geophysics [physics.geo-ph], Université de Grenoble

Bottelin P, Baillet L, Larose E, Jongmans D, Hantz D, Brenguier O, Cadet H, Helmstetter A (2017) Monitoring rock reinforcement works with ambient vibrations: La Bourne case study (Vercors, France). Eng Geol 226:136-145. https://doi.org/10.1016/j.enggeo.2017.06.002

Burjánek J, Gassner-Stamm G, Poggi V, Moore JR, Fäh D (2010) Ambient vibration analysis of an unstable mountain slope. Geophys J Int 180:820-828

Burjánek J, Moore JR, Molina FXY, Fäh D (2012) Instrumental evidence of normal mode rock slope vibration. Geophys J Int 188:559-569

Burjánek J, Gischig V, Moore JR, Fäh D (2018) Ambient vibration characterization and monitoring of a rock slope close to collapse. Geophys J Int 212:297-310. https://doi.org/10.1093/gji/ggx424 
Carrière S (2016) Recherche de précurseurs géophysiques à la transition solide-fluide dans les glissementscoulées affectant les matériaux argileux. PhD thesis in Geophysics [physics.geo-ph], Université de Grenoble

Cekerevac C, Laloui L (2004) Experimental study of thermal effects on the mechanical behaviour of a clay. Int J Numer Anal Meth 28:209-228. https://doi.org/10.1002/nag.332

Chen W-F, Lui EM (1997) Handbook of structural engineering. CRC Press, Boca Raton, Florida

Colombero C, Baillet L, Comina C, Jongmans D, Vinciguerra S (2017) Characterization of the 3-D fracture setting of an unstable rock mass: from surface and seismic investigations to numerical modeling. J Geophys Res Solid Earth 122(8):6346-6366. https://doi.org/10.1002/2017jb014111

Colombero C, Baillet L, Comina C, Jongmans D, Larose E, Valentin J, Vinciguerra S (2018) Integration of ambient seismic noise monitoring, displacement and meteorological measurements to infer the temperature-controlled long-term evolution of a complex prone-to-fall cliff. Geophys J Int 213(3):1876-1897. https://doi.org/10.1093/gji/ggy090

Curtis A, Gerstoft P, Sato H, Snieder R, Wapenaar K (2006) Seismic interferometry-turning noise into signal. Lead Edge 25:1082-1092. https://doi.org/10.1190/1.2349814

Derode A, Larose E, Tanter M, de Rosny J, Tourin A, Campillo M, Flink M (2003) Recovering the Green's function from field-field correlations in an open scattering medium. J Acoust Soc Am 113:2973-2976. https://doi.org/10.1121/1.1570436

Di Donna A, Laloui L (2015) Response of soil subjected to thermal cyclic loading: experimental and constitutive study. Eng Geol 190:65-76. https://doi.org/10.1016/j.enggeo.2015.03.003

Favero V, Ferrari A, Laloui L (2016) Thermo-mechanical volume change behaviour of Opalinus Clay. Int J Rock Mech Min Sci 90:15-25. https://doi.org/10.1016/j.ijrmms.2016.09.013

Fiolleau S, Jongmans D, Bièvre G, Chambon G, Baillet L, Vial B (2020) Seismic characterization of a clayblock rupture in Harmalière landslide, French Western Alps. Geophys J Int. https://doi.org/10.1093/gji/ ggaa050

Hadziioannou C, Larose E, Coutant O, Roux P, Campillo M (2009) Stability of monitoring weak changes in multiply scattering media with ambient noise correlation: laboratory experiments. J Acoust Soc Am 125:3688-3695. https://doi.org/10.1121/1.3125345

Iannucci R, Martino S, Paciello A, D’Amico S, Galea P (2020) Investigation of cliff instability at Ghajn Hadid Tower (Selmun Promontory, Malta) by integrated passive seismic techniques. J Seismolog 24:897-916

Larose E, Derode A, Clorennec D, Margerin L, Campillo M (2005) Passive retrieval of Rayleigh waves in disordered elastic media. Phys Rev E 72:046607. https://doi.org/10.1103/physreve.72.046607

Larose E, Hall S (2009) Monitoring stress related velocity variation in concrete with a $2 \times 10^{-5}$ relative resolution using diffuse ultrasound. J Acoust Soc Am 125:1853-1856

Larose E, Carrière S, Voisin C, Bottelin P, Baillet L, Guéguen P, Walter F, Jongmans D, Guiller B, Garambois S, Gimbert F, Massey C (2015) Environmental seismology: what can we learn on earth surface processes with ambient noise? J Appl Geophys 116:62-74

Lévy C, Baillet L, Jongmans D, Mourot P, Hantz D (2010) Dynamic response of the Chamousset rock column (Western Alps, France). J Geophys Res. https://doi.org/10.1029/2009jf001606

Lowrie W (2007) Fundamental of geophysics. Cambridge University Press, Cambridge

Mainsant G, Larose E, Brönnimann C, Jongmans D, Michoud C, Jaboyedoof M (2012) Ambient seismic noise monitoring of a clay landslide: toward failure prediction. J Geophys Res Earth Surf. https://doi. org/10.1029/2011jf002159

McNamara DE, Buland RP (2004) Ambient noise levels in the continental United States. Bull Seismol Soc Am 94:1517-1527. https://doi.org/10.1785/012003001

Paul A, Campillo M, Margerin L, Larose E, Derode A (2005) Empirical synthesis of time-asymmetrical Green functions from the correlation of coda waves. J Geophys Res. https://doi.org/10.1029/2004jb003521

Poupinet G, Ellsworth WL, Frechet J (1984) Monitoring velocity variations in the crust using earthquake doublets: an application to the Calaveras Fault, California. J Geophys Res 89:5719-5731

Sabra KG, Roux P, Kuperman WA (2005) Arrival-time structure of the time-averaged ambient noise cross-correlation function in an oceanic waveguide. J Acoust Soc Am 117:164-174. https://doi.org/10.1121/1.18355 07

Sato H (2009) Greens function retrieval from the CCF of coda waves in a scattering medium. Geophys J Int 179:1580-1583. https://doi.org/10.1111/j.1365-246x.2009.04398.x

Sens-Schönfelder C, Wegler U (2006) Passive image interferometry and seasonal variations of seismic velocities at Merapi Volcano, Indonesia. Geophys Res Lett. https://doi.org/10.1029/2006g1027797

Shapiro NM, Campillo M (2004) Emergence of broadband Rayleigh waves from correlations of the ambient seismic noise. Geophys Res Lett. https://doi.org/10.1029/2004g1019491

Snieder R (2004) Extracting the Green's function from the correlation of coda waves: a derivation based on stationary phase. Phys Rev E 69:046610. https://doi.org/10.1103/physreve.69.046610 
Starr AM, Moore JR, Thorne MS (2015) Ambient resonance of Mesa Arch, Canyonlands National Park, Utah. Geophys Res Lett 42:6696-6702. https://doi.org/10.1002/2015GL064917

Tourenq C (1970) La gélivité des roches: application aux granulats. Laboratoire Central des Ponts et Chaussées (LCPC)

Tsai VC (2011) A model for seasonal changes in GPS positions and seismic wave speeds due to thermoelastic and hydrologic variations. J Geophys Res 116:B04404. https://doi.org/10.1029/2010JB008156

Valentin J, Capron A, Jongmans D, Baillet L, Bottelin P, Donze F, Larose E, Mangeney A (2017) The dynamic response of prone-to-fall columns to ambient vibrations: comparison between measurements and numerical modelling. Geophys J Int 208:1058-1076. https://doi.org/10.1093/gji/ggw440

Valentin J (2018) Suivi de glissements rocheux et de coulees dans les roches argileuses à partire de methods sismiques et photogrammétriques. $\mathrm{PhD}$ thesis in Geophysics [physics.geo-ph], Université de Grenoble

Wapenaar K (2004) Retrieving the elastodynamic greens function of an arbitrary inhomogeneous medium by cross correlation. Phys Rev Lett 93:254301. https://doi.org/10.1103/physrevlett.93.254301

Weaver RL, Lobkis OI (2001) Ultrasonics without a source: thermal fluctuation correlations at MHz frequencies. Phys Rev Lett 87:134301. https://doi.org/10.1103/physrevlett.87.134301

Weber S, Fäh D, Beutel J, Faillettaz J, Gruber S, Vieli A (2018) Ambient seismic vibrations in steep bedrock permafrost used to infer variations of ice-fill in fractures. Earth Planet Sci Lett 501:119-127

Xia Y, Xu Y-L, Wei Z-L, Zhu H-P, Zhou X-Q (2011) Variation of structural vibration characteristics versus nonuniform temperature distribution. Eng Struct 33:146-153. https://doi.org/10.1016/j.engstruct.2010.09.027

Publisher's Note Springer Nature remains neutral with regard to jurisdictional claims in published maps and institutional affiliations.

\section{Authors and Affiliations}

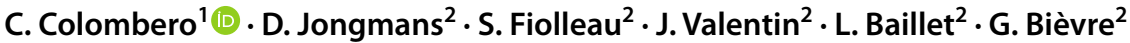

D. Jongmans

denis.jongmans@univ-grenoble-alpes.fr

S. Fiolleau

sylvain.fiolleau@univ-grenoble-alpes.fr

J. Valentin

johann.valentin@univ-grenoble-alpes.fr

L. Baillet

laurent.baillet@univ-grenoble-alpes.fr

G. Bièvre

gregory.bievre@univ-grenoble-alpes.fr

1 Dept. of Environment, Land and Infrastructure Engineering, Politecnico di Torino, Torino, Italy

2 CNRS, IRD, IFSTTAR, ISTerre, Université Grenoble Alpes, Université Savoie Mont Blanc,

Grenoble, France 